\title{
UAV-based Survey of Glaciers in Himalayas: Opportunities and Challenges
}

\author{
RAAJ Ramsankaran ${ }^{1}$, P.J. Navinkumar ${ }^{1}$, Ajay Dashora ${ }^{2}$, A.V. Kulkarni ${ }^{3}$ \\ ${ }^{1}$ Hydro-Remote Sensing Applications (H-RSA) Group, Department of Civil Engineering, Indian Institute of \\ Technology, Bombay, Powai, Mumbai-400076, India \\ ${ }^{2}$ Earth System Science and Engineering, Department of Civil Engineering, Indian Institute of Technology \\ Guwahati, Guwahati, Assam-781039, India \\ ${ }^{3}$ Divecha Centre for Climate Change, Indian Institute of Science, Bengaluru, Karnataka- 560012, India
}

\begin{abstract}
Unmanned Aerial Vehicle (UAV) based remote sensing (RS) studies in glaciology are mainly focusing on obtaining accurate high-resolution data from UAV images. Studies for identifying and minimising the challenges faced during the UAV-based RS data acquisition survey on inaccessible and harsh terrains of mountain glaciers is limited. This study aims to examine the practical challenges faced during UAV surveys of glaciers and derive strategies to minimize them. To the authors' knowledge, this is the first study that addresses such problems over the Himalayan region. Here, the UAV surveys were conducted using a fixed-wing commercialgrade off-the-shelf UAV (eBee plus, SenseFly) on three glacier sites (East Rathong, Hamtah and Panchinala-A) located in different zones and climate regimes lying within the Indian part of Himalayas. From UAV collected photos, the study was able to generate ultra-high-resolution ortho-mosaicked images and Digital Elevation Models (DEMs) at 0.1m GSD. UAV-derived DEMs was able to achieve vertical (horizontal) accuracy of 0.45 and $0.21 \mathrm{~m}(0.15$ and $0.1 \mathrm{~m})$ with 3 and 6 ground control points (GCPs) for an area of $0.75 \mathrm{~km}^{2}$ and $1.38 \mathrm{~km}^{2}$. Accuracy assessment of UAV DEMs generated with and without GCPs indicate that GCPs are must to obtain decimetre level accurate DEM especially on glaciers with steep-valleyed terrains. The utility of the obtained ultra-high-resolution ortho-mosaicked images was demonstrated by generating glacier surface feature maps. Based on the challenges observed during UAV surveys, the study identifies and recommends best-suited locations on a glacier and its adjacent regions for conducting UAV surveys efficiently in the glaciated terrain of Himalayas and possibly beyond. Recommendations reported in this article shall minimise the challenges faced and involved risks for data acquisition and thus enable UAVs to cover more glaciated area successfully.
\end{abstract}

Keywords: Digital Elevation Models, ortho-mosaicked images, glacier, remote sensing, Unmanned Aerial Vehicle 


\section{Introduction}

Glaciers are perennial features that temporarily store freshwater and they comprise only a fraction of the Cryosphere region. Globally, glaciers are losing ice mass in the early twentyfirst century twice that of the end of previous century [1]. In such scenario, continuous monitoring of glaciers at local and regional levels is essential. On a global scale, numerous efforts are being made to observe and monitor glacier health using ground-based, aerial and spaceborne remote sensing platforms, e.g., [2,3,4,5,6,7].

Despite such efforts, only sparse and limited data from ground-based observations are available for reference or validation purposes. Particularly, the Himalayan region in Southwest Asia has significant gaps in ground-based observations [8]. Remoteness and rugged terrains restrict ground-based observations, which are time-consuming and logistically challenging [9]. Though aerial surveys can cover glaciers at a regional scale at required place and time, harsh weather conditions on high altitudes raise safety concerns. Moreover, repetitive aerial surveys are not feasible for glaciological studies due to high costs. Likewise, existing space borne remote sensing platforms have many limitations for collecting individual glacier level accurate data at high resolutions despite having numerous advantages for global scale glacier monitoring [6]. At this juncture, Unmanned Aerial Vehicles (UAV) as remote sensing platform, which can fly below the clouds has enormous potential to augment the sparse and discontinuous field observations by providing ultra-high-resolution images at relatively low costs.

The technological advances in sensors with navigation modules have increased the potential of UAV as a platform for remote sensing [10]. This new potential has led to new facets in acquiring UAV-based remote sensing data such as the ability to acquire ultra-high-resolution, availability of comprehensive spectral as well as geometric data, and fusion of multi-sensor data [11]. Especially, the remarkable development of UAVs with onboard Global Navigation Satellite System/Global Positioning System (GNSS/GPS) receiver; Inertial Measurement Unit (IMU); high endurance capabilities, and 3D model generation by Structure-from-Motion (SfM) process has paved excellent opportunities for deploying UAV-based RS platform in glacier studies [12].

Although the UAV based RS technology is gaining popularity among researchers, certain hurdles such as limited accessibility of alpine glaciers and the challenges related to flying in high altitudes are hindering the progress of UAVs in glacier research, especially in high mountain alpine regions such as the Himalayas. This is evident from the geographical 
distribution of available studies, where around $90 \%$ of the UAV-based glaciology applications are focussed on polar and sub-polar regions, while few studies, i.e. 10\% are only focussed on the Alpine regions [12].

Despite such challenges, in recent years the application of UAVs in Alpine regions (i.e. the Andes, the Alps, the Himalayas) are gaining momentum although still comparatively lower than the Polar and Sub-polar regions [13,14,15,16,17,18,19,20]. Till date, studies demonstrating the UAV applications in Himalayas remain scarce and are focussed only on three glaciers namely, Lirung; Changri Nup and Thulagi glacier areas in Nepal $[21,22,23,24,25,26]$. It is because the terrain of the glaciers in Himalayas are hostile, highly debris-covered, located at high altittudes (the average elevation of the Himalayas is significantly higher than the Alps and the Andes mountain ranges) making logistics and movements much more difficult. Morerover, applying UAV photogrammetry to the Himalayan glaciers poses additional challenges such as low air pressure, poor GNSS receptions for UAVs with automatic navigations.

As stated in Groos et.al. [27], except few e.g., [28,29], most of the glaciological studies use Commercial off-the-shelf (COTS) UAVs to acquire aerial images in a high spatial resolution e.g., [20,30,31]. The benefit of commercial UAVs is obvious: they are reliable and ready-touse. It is also observed that most of the UAV-based glaciological studies e.g., [21,28,32,33,34] use fixed-wing UAVs rather than rotary-wing UAVs. This is mainly due to the advantages of fixed-wing UAVs in providing better aerodynamics, longer flight duration, cover comparatively larger area per flight and fly higher than rotary-wing [12]. However, great care is required in identifying proper take-off and landing sites in rugged mountainous terrain to prevent physical damages to the fixed-wing UAVs.

On the other hand, to obtain accurate glacier topography, UAV based SfM methods rely on Ground Control Points (GCPs). Recent study by Gindraux et al. [32] reported that on all seasons 17(7) GCPs per $\mathrm{km}^{2}$ are required to achieve Digital Surface Model (DSM) with vertical (horizontal) accuracy of range 0.1-0.25m (0.03-0.09m). Follwing this, other glacier studies have also used GCPs (varying between seven and seventeen) to generate DEMs between centimetre and decimetre level accuracies e.g., [15,27,31]. However, the topography of most of the glaciers in Himalayan region is complex where collecting minimum GCPs are impractical due to safety reasons. 
Despite the increasingly common use of UAVs in glaciology, there are several technical and practical challenges that have yet to be completely overcome when operating UAVs in extreme, high mountain regions. Therefore, studies addressing the practical challenges of UAV surveys in inaccessible terrain and harsh meteorological conditions like Himalayas are very much essential. Towards filling this gap, this article collates the authors' experiences gained from UAV-based surveys carried out at glaciers located in different river basins in Indian Himalayas. This study used COTS fixed-wing UAV (Sensefly eBee plus) mounted with digital RGB camera to acquire images on the ablation regions of the study glaciers. The study aims to,

- Examine the practical challenges faced during UAV surveys of glaciers and their impacts on the UAV data products.

- Generate Digital Elevation Models (DEMs) from UAV collected images and assess the elevation accuracy and

- Provide possible strategies and suggestions to identify take-off/landing locations for conducting efficient UAV surveys using COTS fixed-wing UAVs. 


\section{Study Sites}

UAV surveys were conducted on three glaciers, namely East Rathong, Hamtah and PanchinalaA in Indian Himalayan region. Details of the location, areal extent, elevation, and debris cover of these glaciers are given in Table 1 . Figure 1 shows the locations of the study glaciers and the area covered by the UAV surveys.

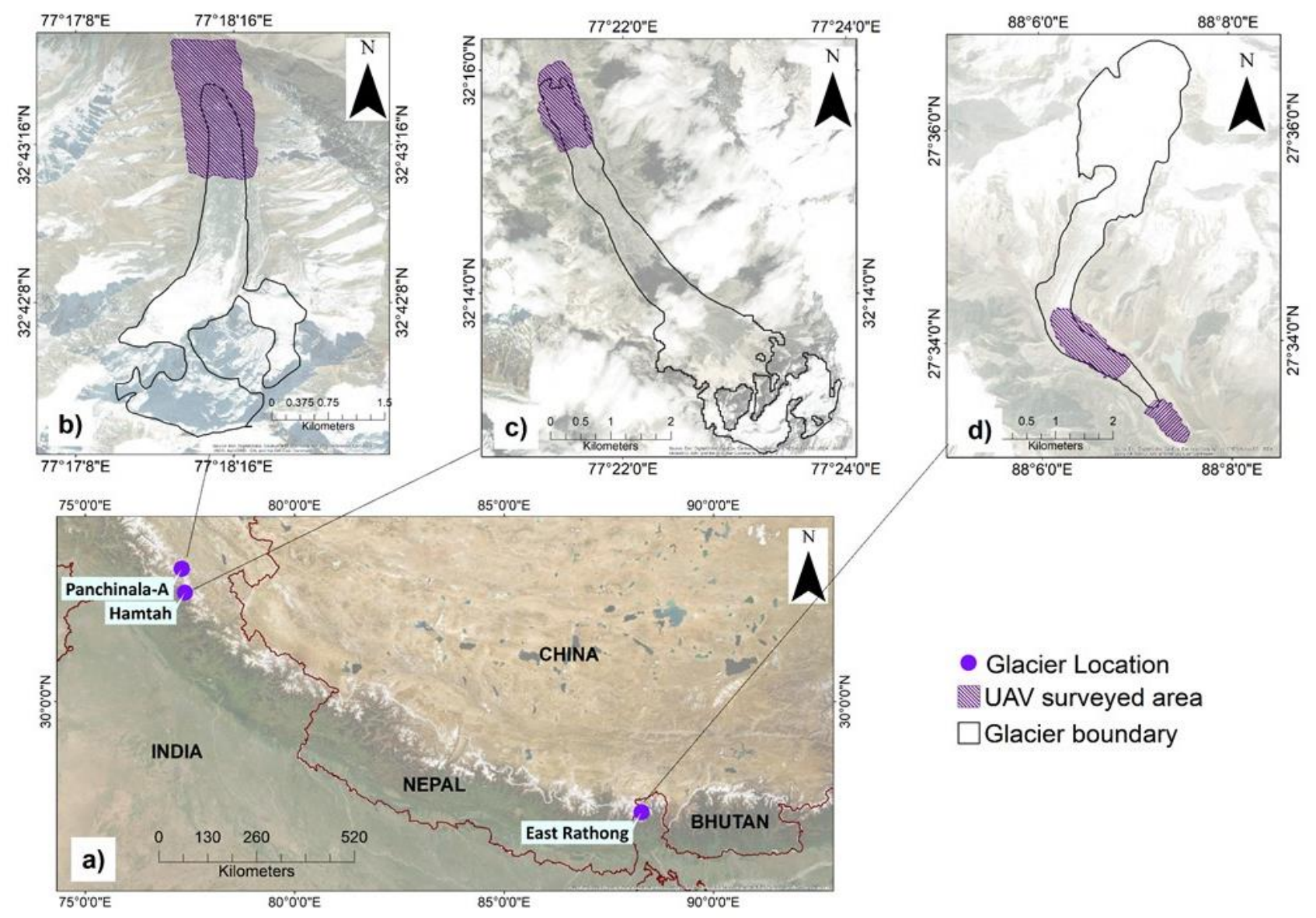

Figure 1: The map shows locations of the Hamtah and Panchinala-A glaciers in Himachal Pradesh and East Rathong glacier in Sikkim (a); Individual glacier boundaries (black outline) of East Rathong (d), Hamtah (c) and Panchinala-A (b) with the boundaries of UAV surveyed area (violet). Background image source: Esri, DigitalGlobe, GeoEye, i-cubed, USDA FSA, USGS, AEX, Getmapping, Aerogrid, IGN, IGP, swisstopo, and the GIS User Community. 
Table 1: Details of the study glaciers

\begin{tabular}{|c|c|c|c|c|c|c|c|}
\hline \multirow{2}{*}{$\begin{array}{l}\text { S. } \\
\text { No. }\end{array}$} & \multirow{2}{*}{ Glacier } & \multicolumn{2}{|c|}{ Location } & \multirow{2}{*}{$\begin{array}{c}\begin{array}{c}\text { Areal Extent } \\
\left(\mathrm{km}^{2}\right)\end{array} \\
\text { Total } \\
\text { (Debris cover) }\end{array}$} & \multirow{2}{*}{$\begin{array}{c}\text { Mean } \\
\text { Elevation } \\
(\sim \text { m a.s.l. })\end{array}$} & \multirow{2}{*}{$\begin{array}{l}\text { Length } \\
(\mathrm{km})\end{array}$} & \multirow{2}{*}{$\begin{array}{c}\text { Basin } \\
\text { (Region) }\end{array}$} \\
\hline & & Latitude & Longitude & & & & \\
\hline 1 & $\begin{array}{l}\text { East } \\
\text { Rathong }\end{array}$ & $\begin{array}{l}27^{\circ} 34^{\prime} \mathrm{N} \text { to } \\
27^{\circ} 37^{\prime} \mathrm{N}\end{array}$ & $\begin{array}{l}88^{\circ} 06^{\prime} \text { E to } \\
88^{\circ} 08^{\prime} \mathrm{E}\end{array}$ & $6.06(0.91)$ & 5760 & 7.10 & $\begin{array}{l}\text { Teesta basin } \\
\text { (Eastern } \\
\text { Himalayas) }\end{array}$ \\
\hline 2 & Hamtah & $\begin{array}{l}32^{\circ} 12^{\prime} \mathrm{N} \text { to } \\
32^{\circ} 18^{\prime} \mathrm{N}\end{array}$ & $\begin{array}{l}77^{\circ} 18^{\prime} \mathrm{E} \text { to } \\
77^{\circ} 41^{\prime} \mathrm{E}\end{array}$ & $3.24(2.37)$ & 4688 & 6.00 & $\begin{array}{l}\text { Chandra } \\
\text { Basin } \\
\text { (Western } \\
\text { Himalayas) }\end{array}$ \\
\hline 3 & $\begin{array}{l}\text { Panchin } \\
\text { ala-A }\end{array}$ & $\begin{array}{l}32^{\circ} 41^{\prime} \mathrm{N} \text { to } \\
32^{\circ} 44^{\prime} \mathrm{N}\end{array}$ & $\begin{array}{l}77^{\circ} 17^{\prime} \text { E to } \\
77^{\circ} 19^{\prime} \mathrm{E}\end{array}$ & $4.11(1.19)$ & 4930 & 4.87 & $\begin{array}{l}\text { Bhaga Basin } \\
\text { (Western } \\
\text { Himalayas) }\end{array}$ \\
\hline
\end{tabular}

East Rathong is a South-East facing summer nourished valley glacier [35] and it is the only benchmark glacier in the Eastern Indian Himalayan region, which is being monitored regularly from 2013 [36]. This glacier is covered by debris, i.e. 15\% of total glacier area and surrounded by steep lateral walls at the lower ablation regions. It originates at $\sim 6800 \mathrm{~m}$ above sea level (a.s.l.) and terminates at $\sim 4720 \mathrm{~m}$ a.s.1.

Hamtah glacier is a North facing valley glacier fed by the mid-latitude westerlies. This glacier is one of the benchmark glaciers in Western Indian Himalayas being monitored since the early 2000s [37]. This glacier is mostly covered by debris, i.e. $73 \%$ of total glacier area and also surrounded by steep lateral walls. The glacier is $\sim 6 \mathrm{~km}$ long with an average width of $0.5 \mathrm{~km}$ and lies within the elevation range of 4000 - $5000 \mathrm{~m}$ a.s.l.

Following [38], the glacier in Figure $1 \mathrm{~b}$ is named as Panchinala-A. The Panchinala-A glacier is North facing valley glacier which also lies in the Western Indian Himalayan region nourished by mid-latitude westerlies. The glacier is covered by debris i.e. $29 \%$ of total glacier area and has less steep walls than that of the other study glaciers. The glacier is $\sim 5 \mathrm{~km}$ long with an average width of $\sim 0.55 \mathrm{~km}$ and lies within the elevation range of 4300 - $5990 \mathrm{~m}$ a.s.1. 


\section{Methods}

The study consists of three stages: data acquisition, data processing, and preparation of data products. Figure 2 illustrates the methods adopted in these three stages. First, data acquisition activities by UAV and the Differential Global Positioning System (DGPS) are discussed for all the three study glaciers. Following this, the processing of collected UAV photos and GCPs through DGPS observations are discussed. Finally, the observations inferred from the UAV extracted data products such as Ortho-mosaicked images, DEMs and their slope characteristics are reported and discussed.

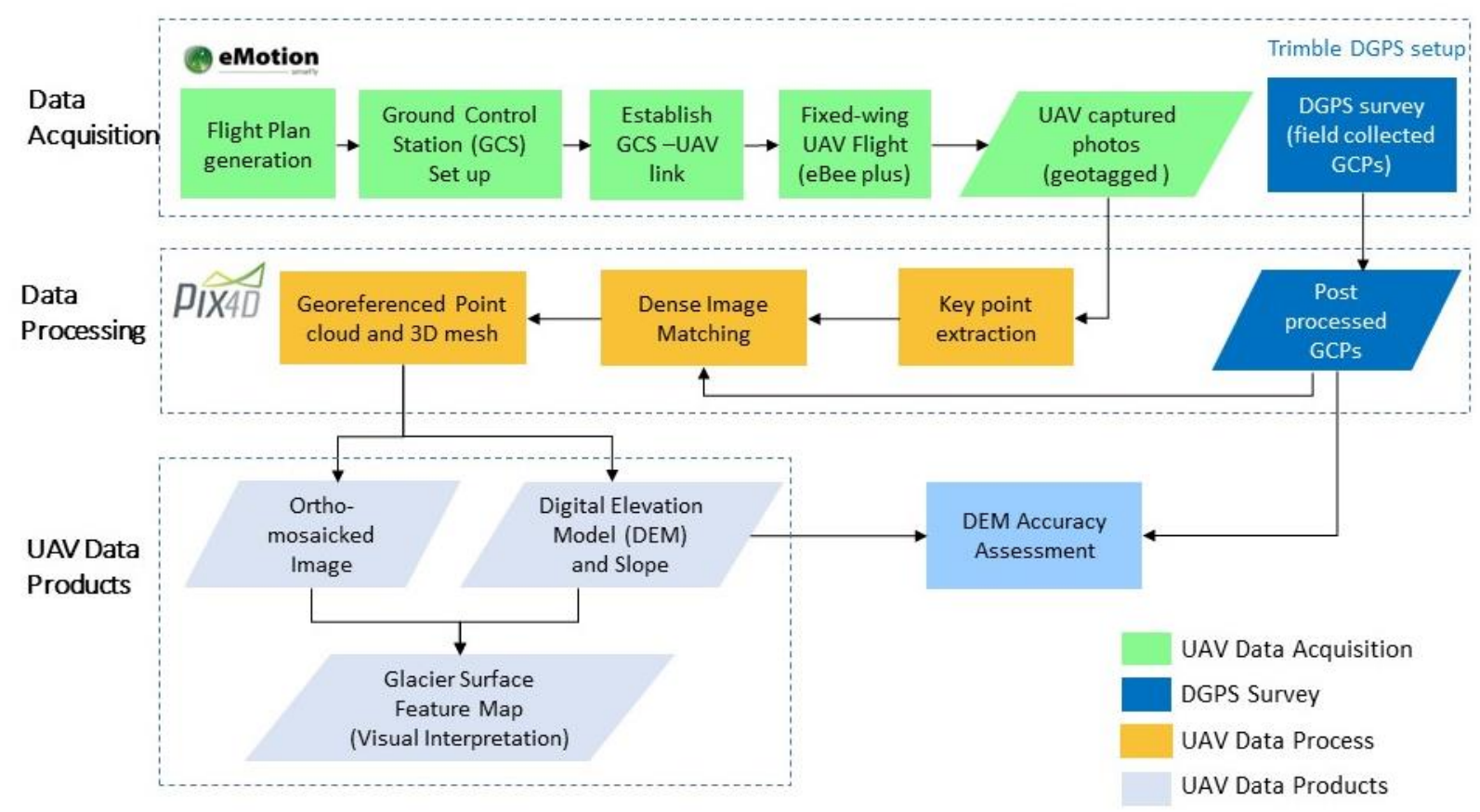

Figure 2: Block diagram of the processes adopted for UAV in different stages, data acquisition, data processing and data products generation.

\subsection{Data Acquisition}

\subsubsection{UAV Setup and Specifications}

To conduct the UAV survey, a commercial-grade off-the-shelf fixed-wing UAV (eBee plus, Sensefly) was used. This UAV has a central body, detachable fixed wings and a propeller at the tail. It is equipped with an onboard Global Navigation Satellite System (GNSS) module and Inertial Measurement Unit (IMU) modules. The hardware component weighs approximately $1.2 \mathrm{~kg}$, including battery and RGB camera module. Two-mode of GNSS acquisition is possible in this UAV, i.e. standalone, and RTK mode. Here the UAV surveys 
were carried out in standalone mode. The camera module of the UAV was equipped with Sony DSC-WX220 (for East Rathong and Hamtah glaciers) and SenseFly's Sensor Optimized for Drone Applications (SODA) (for Panchinala-A glacier) RGB cameras. The SODA camera is the first sensor, explicitly built for professional drone photogrammetry. The UAV setup used and their specifications along with the software used for flight planning and data processing are given in Table 2 .

Table 2: Specifications of the UAV setup and software used in the study

\begin{tabular}{|c|c|c|c|}
\hline UAV setup & Type (Model name) & \multicolumn{2}{|c|}{ Specifications/Applications } \\
\hline \multirow[t]{3}{*}{ Hardware } & $\begin{array}{c}\text { Fixed Wing (Sensefly eBee } \\
\text { plus) }\end{array}$ & \multicolumn{2}{|c|}{$\begin{array}{l}\text { Dimensions: } 55 \times 45 \times 25 \mathrm{~cm} \\
\text { Weight: } ~ 1.2 \mathrm{~kg} \text { (with the RGB camera module and } \\
\text { battery) } \\
\text { Material: EPP foam and carbon } \\
\text { Battery: } 3700 \mathrm{mAh} \text { (Lithium polymer) } \\
\text { Speed: } 40-90 \mathrm{~km} / \mathrm{hr} \text {. } \\
\text { Inbuilt GNSS (GPS \& GLONASS)/IMU unit } \\
\text { Wind resistance Up to } 45 \mathrm{~km} / \mathrm{hr}\end{array}$} \\
\hline & $\begin{array}{c}\text { Radio Frequency (RF) } \\
\text { Modem } \\
\end{array}$ & \multicolumn{2}{|c|}{$\begin{array}{l}\text { Establish a link between the drone and the flight } \\
\text { management software }\end{array}$} \\
\hline & $\begin{array}{l}\text { Camera type(RGB) } \\
\text { Sensor dimension } \\
(\mathrm{mm} \times \mathrm{mm})\end{array}$ & $\begin{array}{l}\text { SONY DSC-WX220 } \\
6.170 \times 4.627\end{array}$ & $\begin{array}{l}\text { S.O.D.A } \\
13.133 \times 8.755\end{array}$ \\
\hline \multirow{2}{*}{ Software } & $\begin{array}{l}\text { Automated Flight } \\
\text { management software } \\
\text { (eMotion 3) }\end{array}$ & \multicolumn{2}{|c|}{ 3D flight plan and automated flight execution } \\
\hline & $\begin{array}{c}\text { UAV photogrammetric } \\
\text { software } \\
\text { (Pix4D Mapper) }\end{array}$ & \multicolumn{2}{|c|}{$\begin{array}{l}\text { Post-Processing UAV collected photos, Ortho- } \\
\text { mosaicked image and DEM generation }\end{array}$} \\
\hline
\end{tabular}

\subsubsection{DGPS Survey}

Prior to UAV survey, DGPS surveys were conducted on all three study glaciers to georeference and validate the ortho-mosaicked images and DEMs (Table 3). The DGPS setup included one rover and base station (Trimble Zephyr antennas) with two handheld controllers (GeoExplorer GeoXH handheld). The field photos taken on surveyed sites are shown in Figure 3. Figures 3a, $3 \mathrm{~b}$ and $3 \mathrm{c}$ show the terrain captured near to the glacier snout region of East Rathong, Hamtah and Panchinala-A glacier respectively. Figures $3 \mathrm{~d}$ and $3 \mathrm{e}$ show the senseFly eBee plus fixedwing UAV setup and take-off at Hamtah glacier, respectively. Whereas, Figures $3 \mathrm{f}$ and $3 \mathrm{~g}$ show the DGPS survey conducted at Panchinala-A glacier respectively. Artificial GCP targets 
(dimension $1 \mathrm{~m} \times 1 \mathrm{~m}$ ) were made of synthetic clothes with the yellow-black and yellow-red combinations. GCPs were collected on the central point of the artificial targets.

Table 3: Ground survey list of GCPs with elevation, date and time of DGPS data collection.

\begin{tabular}{|c|c|c|c|c|}
\hline \multirow{2}{*}{$\begin{array}{c}\text { Study } \\
\text { Glaciers }\end{array}$} & \multicolumn{2}{|c|}{ DGPS survey details } & \multirow{2}{*}{$\begin{array}{c}\text { Total GCPs collected } \\
\text { (GCPs within the UAV } \\
\text { surveyed area) }\end{array}$} & \multirow{2}{*}{$\begin{array}{l}\text { Number of } \\
\text { Check Points } \\
\text { (CP) used } \\
\end{array}$} \\
\hline & Date & Elevation (m) & & \\
\hline $\begin{array}{c}\text { East } \\
\text { Rathong }\end{array}$ & 02-10-2017 & $\begin{array}{l}4657.833 \\
4627.535 \\
4618.103 \\
4611.077 \\
4613.334 \\
4605.301\end{array}$ & $6(-)$ & - \\
\hline & 20-09-2018 & $\begin{array}{l}4012.274 \\
4010.142 \\
4010.105 \\
4046.439 \\
4084.995\end{array}$ & & \\
\hline Hamtah & 21-09-2018 & $\begin{array}{l}4135.590 \\
4196.704 \\
4217.000 \\
4260.980 \\
4314.276 \\
4325.920 \\
3983.737 \\
3976.487 \\
3979.729 \\
3953.747 \\
3954.330 \\
\end{array}$ & $15(3)$ & 2 \\
\hline $\begin{array}{c}\text { Panchinal } \\
\text { a-A }\end{array}$ & 14-06-2019 & $\begin{array}{l}4324.793 \\
4315.976 \\
4299.974 \\
4259.891 \\
4215.826 \\
4206.834 \\
4195.622 \\
4204.626 \\
4216.628\end{array}$ & $9(6)$ & 3 \\
\hline
\end{tabular}



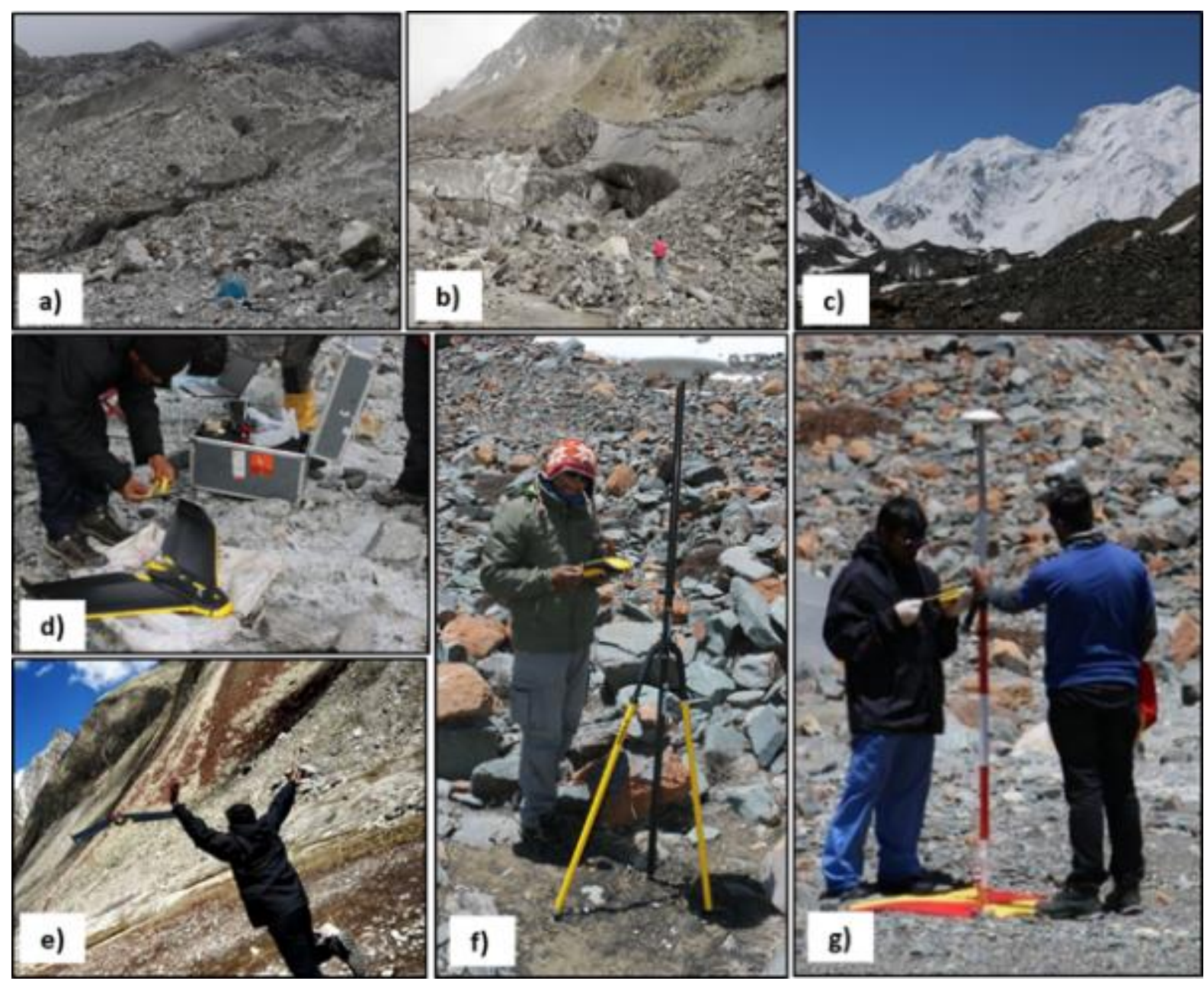

Figure 3: Field photos collected at the glacier sites. Terrain near the snout region of the East Rathong (a), Hamtah (b) and Panchinala-A (c) glaciers respectively; Fixed-wing UAV set-up (d) and UAV take-off (e) at the Hamtah glacier site respectively; Base station setup (f) and Rover setup (g) for GCP collection at Panchinala-A glacier respectively.

\subsection{UAV Flight Plan Design and Survey}

The UAV survey flight missions were planned and executed with the eMotion version 3 software package. The communication is established between the flight management software and the UAV via a radio frequency (RF) modem. The setup, i.e. laptop with flight management software (eMotion v3) and RF modem, tends to act as ground control station (GCS). With the eMotion software, flight plans are generated as mission blocks with the flight parameters (ceiling height, the radius of UAV coverage area, UAV take-off and landing, and mission block generation) and SRTM DEM of a given terrain. Table 4 shows the data acquisition 
characteristics of the UAV mission plan adopted for the selected glacier sites. The fixed-wing UAV takes-off with a motion sensor technology, i.e. by moving UAV back and forth three to four times to launch the UAV. Minimum $2 \mathrm{~ms}^{-1}$ wind speed is required to fly the fixed-wing UAV. However, on all the surveyed sites, an average wind speed was observed to vary between $4 \mathrm{~ms}^{-1}$ and $6 \mathrm{~ms}^{-1}$ at the time of UAV flights. All the flight missions were pre-set and automated within eMotion software. At East Rathong, UAV survey was conducted in two locations, viz, (i) on ablation region of the glacier (referred as ER1) and (ii) below the glacier terminus i.e. stable ground on 2 October 2017 (referred as ER2) (Figure 4a). Whereas, at Hamtah (Figure 4b) and Panchinala-A (Figure 4c) sites, UAV surveys were conducted at the lower portion of the glaciers covering some portion of ablation area and stable ground surface. The areal extents and photo locations captured by UAV, GCPs, checkpoints, DGPS base station locations, and UAV take-off locations at East Rathong, Hamtah and Panchinala-A glaciers are also shown in Figures $4 \mathrm{a}, 4 \mathrm{~b}$ and $4 \mathrm{c}$.

Table 4: Data acquisition details of the UAV survey carried out in the study glaciers

Glacier Sites East Rathong Hamtah Panchinala-A

Survey dates

$2 \& 3$ October $2017 \quad 20$ October $2018 \quad$ 14 June 2019

Distance between photos $(\mathrm{m})$

36

36

36

Distance between flight line (m)

78

78

66

Single image swath (m)

196x144

196x144

$219 \times 146$

Overlap : Side x Frontal (m)

$60 \times 75$

$60 \times 75$

$70 \times 75$

Observed average wind speed $\left(\mathrm{ms}^{-1}\right)$

during flight

$\sim 5$

$\sim 4$

$\sim 6$

Mode of landing

Linear

Linear

Linear 


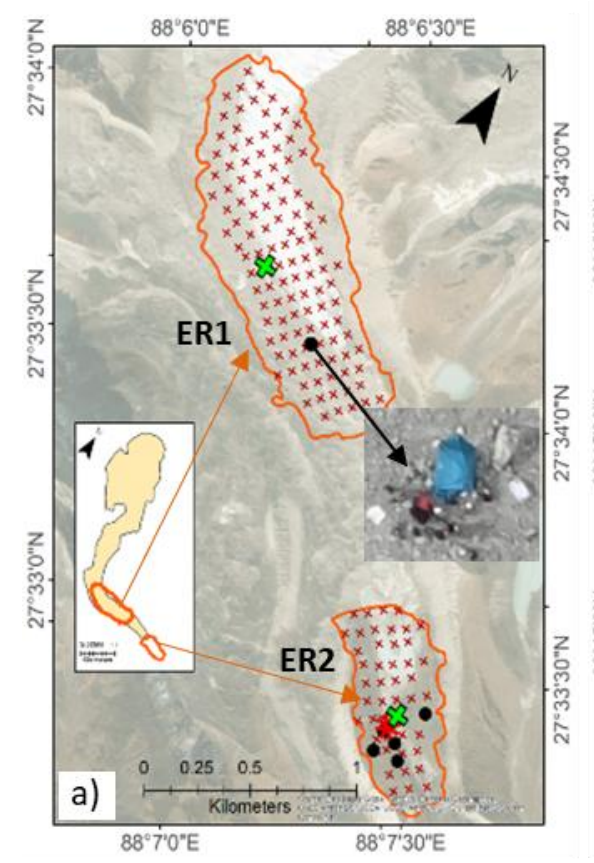

$\square$ UAV Coverage area

$\square$ Glacier Area

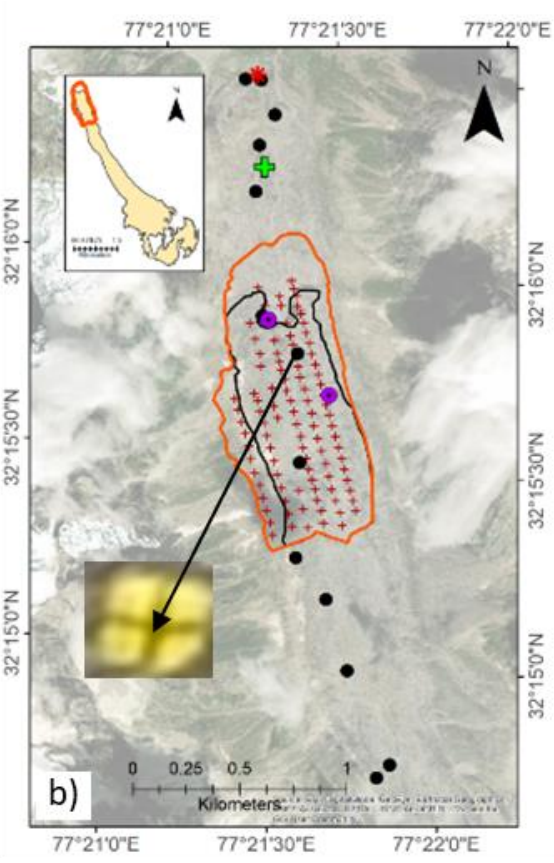

* DGPS Base station

- Ground Control Points

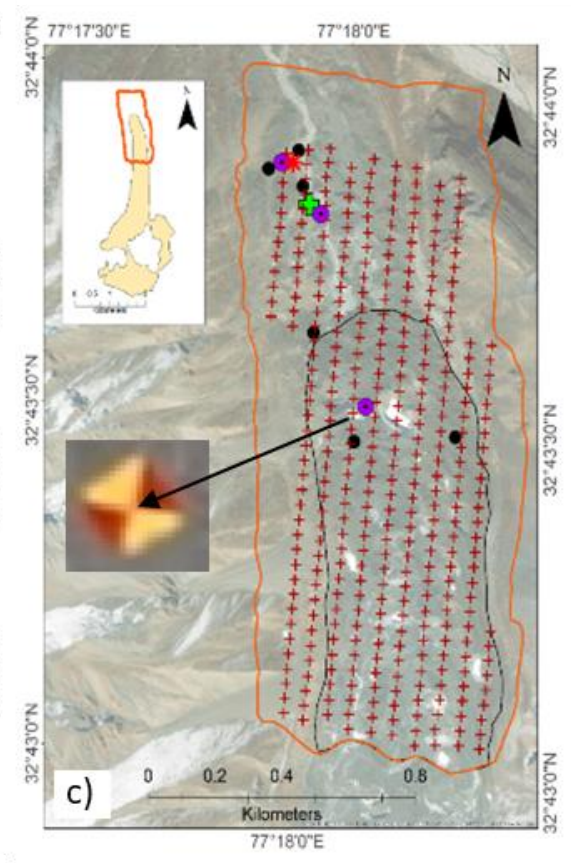

Check points

+ Captured image location ك UAV Take off

Figure 4: Maps of UAV coverage area (orange outline) and glacier area (black outline) on a)

East Rathong ER1 and ER2, b) Hamtah and c) Panchinala-A glacier region; The inset maps in a), b) and c) are the glacier boundaries with UAV coverage area. Background image source: Esri, DigitalGlobe, GeoEye, i-cubed, USDA FSA, USGS, AEX, Getmapping, Aerogrid, IGN, $I G P$, swisstopo, and the GIS User Community.

\subsection{UAV Ortho-mosaicked Images and DEM Extraction}

From the acquired UAV geotagged images, data products such as ortho-mosaicked images and DEMs were generated using the Pix4D Mapper software, which uses the Structure for Motion (SfM) technique. As there were no trees, grass or any other features present above the surface, UAV derived DSM is considered as DEM throughout this study. The Pix4D mapper processed the photos in three stages: initial processing, generation of point cloud and mesh and finally ortho-mosaicked image and DEM generation. The UAV collected photos were referenced with WGS84 (EGM 96 Geoid) datum and the output coordinate system was set as WGS 84, UTM Zone 43N for the Hamtah and the Panchinala-A glaciers and WGS84, UTM Zone 45N for the East Rathong glacier.

In the initial processing stage, the image scale size was set to the UAV acquired image scale; key point extraction was set to an automatic mode where the images are matched to compute 
key points, and then automatic tie points are built and analysed. Following this, standard calibration mode was set to optimise the camera parameters.

To improve accuracy, the georeferencing process was carried out by accurately identifying the central points of the collected GCPs targets on three surveyed sites. Following Rossini et al. [31], among the GCPs available within the UAV surveyed site, two-third of them were used for georeferencing and one-third for validation. In East Rathong site, out of 6 GCPs, 5 GCPs were collected at ER2 and one GCP at ER1. Due to insufficient GCPs at ER1, georeferencing and validation was not possible. However, at ER2 the georeferencing was done with all 5 collected GCPs sparing none for validation. It is because the GCPs were confined in a small area and hence, validating in such scenarios is not appropriate. At Hamtah site, out of 5 GCPs, 3(2) GCPs were used for georeferencing (validation). Likewise, in Panchinala-A, out of 9 GCPs, 6(3) GCPs were used for georeferencing (validation).

In the next stage to generate the dense point cloud and mesh, image scale size was set to half of the image size and default optimal level option was set to generate dense point clouds. From the generated dense point cloud and mesh, ortho-mosaicked images and DEMs were reconstructed. Apart from the georeferencing and validation with GCPs, the same procedure was followed to generated ortho-mosaicked images and DEMs for all the three glacier sites.

\section{Results}

At East Rathong site, with two flights the fixed-wing UAV (eBee plus) was able to cover 0.78 $\mathrm{km}^{2}$ area in $\sim 21$ minutes in ER1 and $0.29 \mathrm{~km}^{2}$ area in $\sim 6$ minutes in ER2 at an average altitude of $\sim 215 \mathrm{~m}$ above the ground level. Whereas, in Hamtah site, a single flight by the UAV covered $0.75 \mathrm{~km}^{2}$ area in $\sim 45$ minutes at an average altitude of $\sim 140 \mathrm{~m}$ above the ground level; At Panchinala-A site, a single flight by the UAV covered $1.38 \mathrm{~km}^{2}$ area in $\sim 30$ minutes at an average altitude $\sim 170 \mathrm{~m}$ above the ground level. The above-surveyed sites include both glacier and non-glacier regions. Among these, UAV covered 12.80\%, $15.70 \%$ and $13.86 \%$ of the total glacier area in East Rathong, Hamtah and Panchinala-A glaciers respectively. For all three surveyed sites, the ortho-mosaicked images and DEMs were processed with $10 \mathrm{~cm} /$ pixel GSD. The UAV coverage area and their flight-related aspects for the selected three glacier sites are shown in Table 5. 
Table 5: Details of UAV coverage area and flight-related information of the three glacier sites.

\begin{tabular}{|l|l|c|c|c|}
\hline \multicolumn{2}{|c|}{ UAV surveyed area and related information } & East Rathong & Hamtah & Panchinala-A \\
\hline Coverage area & $\begin{array}{l}\text { Total Glacier area (\$ UAV } \\
\text { surveyed area) }\left(\mathrm{km}^{2}\right) \\
\text { Glacier area covered by UAV } \\
\left(\mathrm{km}^{2}\right)\end{array}$ & $6.06(1.07)$ & $3.24(0.75)$ & $4.11(1.38)$ \\
No of Photos & 0.78 & 0.51 & 0.57 \\
\hline $\begin{array}{l}\text { Flightpath and } \\
\text { altitude }\end{array}$ & $\begin{array}{l}\text { Flightpath distance (km) from } \\
\text { take-off to landing } \\
\text { Flight duration (minutes) } \\
\text { Flight Altitude above the ground } \\
\text { level (AGL) (m) }\end{array}$ & 135 & 107 & 360 \\
\hline $\begin{array}{l}\text { Onboard GNSS } \\
\text { (GPS/GLONASS) } \\
\text { module }\end{array}$ & No. of satellite signals received & $3-4$ & 21.7 & 27.2 \\
\hline
\end{tabular}

${ }^{\$} \mathrm{UAV}$ surveyed area includes glacier and non-glacier region

\subsection{Accuracy Assessment}

\section{GCP Accuracy}

For accuracy assessment of the UAV generated DEMs, GCPs collected during the DGPS survey were used. The DGPS survey collected six GCPs on the East Rathong region in ER1 and ER2, fifteen GCPs on the Hamtah and nine GCPs on the Panchinala-A sites (see Table 2). The collected GCPs were then post-processed using Trimble Path Finder Office software package. The positional accuracy of the base corrected GCPs in the East Rathong region has $96 \%$ of the processed sample points ranged within 5-15 cm, for Hamtah region $82 \%$ of processed sample points ranged within $5-50 \mathrm{~cm}$, and $95 \%$ of sample points ranged within 5-15 cm for Panchinala-A region.

\section{Accuracy of UAV-derived DEMs}

To ascertain the effects of GCPs on UAV data products accuracy, UAV-derived DEMs were generated with and without GCPs for all the three surveyed sites. Care was taken that DGPS collected GCPs and UAV-derived DEMs were at the same coordinate system. In the case of ER2 (Hamtah) surveyed sites, DEM generated without GCPs shows a vertical root mean square error (RMSE) of 31.83m (21.52m) and horizontal RMSE of 1.74m (4.29m) (Table 6). Whereas, in Panchinala-A site, the DEM generated without GCPs shows vertical RMSE of $0.63 \mathrm{~m}$ and 
horizontal RMSE of $2.88 \mathrm{~m}$, which is lower than the other two surveyed sites. Higher errors in UAV-derived DEMs (without GCPs) at ER2 and Hamtah sites could be due to (i) instability of the flying UAV because of air turbulence and (ii) the presence of steep glacier valleys which obstructed the GNSS satellite signals. However, at Panchinala-A site, vertical error in the DEM (without GCPs) is comparatively lower than that of ER2 and Hamtah sites but not the horizontal error (Table 6).

Table 6: Root Mean Square Error (RMSE) of DEMs generated from Pix4D without GCPs, with GCPs and from the checkpoints on East Rathong (ER2), Hamtah and Panchinala-A sites. $\mathrm{R}_{\mathrm{xy}}, \mathrm{R}_{\mathrm{z}}$ denotes RMSE of horizontal ( $\mathrm{x}$ and $\mathrm{y}$ ) and vertical ( $\mathrm{z}$ ) surface, respectively.

\begin{tabular}{|c|cc|cc|cc|}
\hline \multirow{2}{*}{ Glacier name } & \multicolumn{6}{|c|}{ RMSE of UAV derived DEMs } \\
\cline { 2 - 7 } & \multicolumn{2}{|c|}{ Without GCP(s) } & \multicolumn{2}{c|}{ With GCPs } & \multicolumn{2}{c|}{$\begin{array}{c}\text { With Checkpoints } \\
\text { (during validation) }\end{array}$} \\
\cline { 2 - 7 } & $\mathrm{R}_{\mathrm{xy}}(\mathrm{m})$ & $\mathrm{R}_{\mathrm{z}}(\mathrm{m})$ & $\mathrm{R}_{\mathrm{xy}}(\mathrm{m})$ & $\mathrm{R}_{\mathrm{z}}(\mathrm{m})$ & $\mathrm{R}_{\mathrm{xy}}(\mathrm{m})$ & $\mathrm{R}_{\mathrm{z}}(\mathrm{m})$ \\
\hline $\begin{array}{c}\text { East Rathong } \\
\text { (ER2) }\end{array}$ & 1.74 & 31.83 & 0.04 & 1.49 & - & - \\
\hline Hamtah & 4.29 & 21.52 & 0.04 & 0.06 & 0.15 & 0.45 \\
\hline Panchinala-A & 2.88 & 0.63 & 0.03 & 0.08 & 0.10 & 0.21 \\
\hline
\end{tabular}

By georeferencing the DEMs (with GCPs) on three glacier sites, significant improvement in horizontal and vertical accuracies are observed at ER2 and Hamtah sites. However, for Panhci Nala-A, error in the generated DEM (without GCPs) was already less and hence, only minor improvement is observed in the DEMs (with GCPs). Finally, when a validation of the generated DEMs (with GCPs) was carried out with available checkpoints (CPs), the results show that the vertical (horizontal) accuracy of the derived DEM is $0.45 \mathrm{~m}(0.15 \mathrm{~m})$ at Hamtah site and 0.21 $\mathrm{m}(0.10 \mathrm{~m})$ at Panchinala-A site.

Detailed analysis, indicate that the target type (stable natural feature/artificial targets) used for collecting GCPs also influences the DEM accuracy to some extent. In Table 5, the vertical error of DEMs (with GCPs) at ER2 was 1.49m, which is comparatively higher than that of vertical errors at Hamtah and Panchinala-A sites. This is because at ER2 the GCPs were collected on stable natural features and identifying the central point on natural targets while generating the DEM (Sec. 3.3) are less obvious as discussed by Ewertowski et al. [39]. Whereas, at Hamtah and Panchinala-A sites GCPs were collected on artificial targets and was able to accurately 
locate central points on their targets while generating DEMs (Sec. 3.3). For illustration, the visible natural GCP target (Figure 4a) and artificial GCP targets (Figures $4 \mathrm{~b}$ and $4 \mathrm{c}$ ) on the three study glacier sites are shown in Figure 4.

\subsection{Glacier Topography and Surface Features Maps}

\subsubsection{Topography Maps}

For the UAV surveyed area at three study sites, DEMs and their respective slope maps were generated. Topographic map of the surveyed area of the East Rathong glacier site at ER1 shows that surface elevation ranges from $4619 \mathrm{~m}$ a.s.l to $4803 \mathrm{~m}$ a.s.l with an average slope of $15.30^{\circ}$ (Figure 5a). At ER2, which is on stable ground located below the glacier terminus region, the surface elevation ranges from $4573 \mathrm{~m}$ a.s.1 to $4673 \mathrm{~m}$ a.s.1 with an average slope of $16.24^{0}$ (Figure 5b). In Hamtah glacier site, surface elevation ranges from $3988 \mathrm{~m}$ a.s.1 to $4236 \mathrm{~m}$ a.s.1 with an average slope of $21.30^{\circ}$ (Figure 5c). Here ice-cliffs were observed to have steeper slopes and dominant at the left region and glacier snout region. The Panchinala-A glacier (Figure 5d) DEM and slope maps show that the elevation ranges from $4163 \mathrm{~m}$ a.s.1 to $4489 \mathrm{~m}$ a.s.1 with an average slope of $21.73^{\circ}$. From the generated slope maps, it is observed that the ablation region of the Panchinala-A and the Hamtah glacier terrains are more undulated than the East Rathong glacier. 

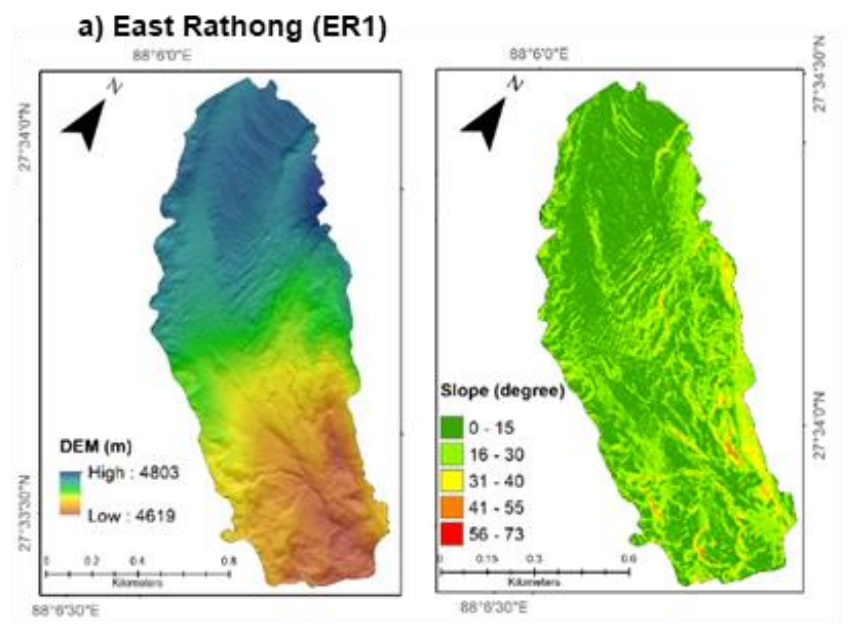

\section{b) East Rathong (ER2)}

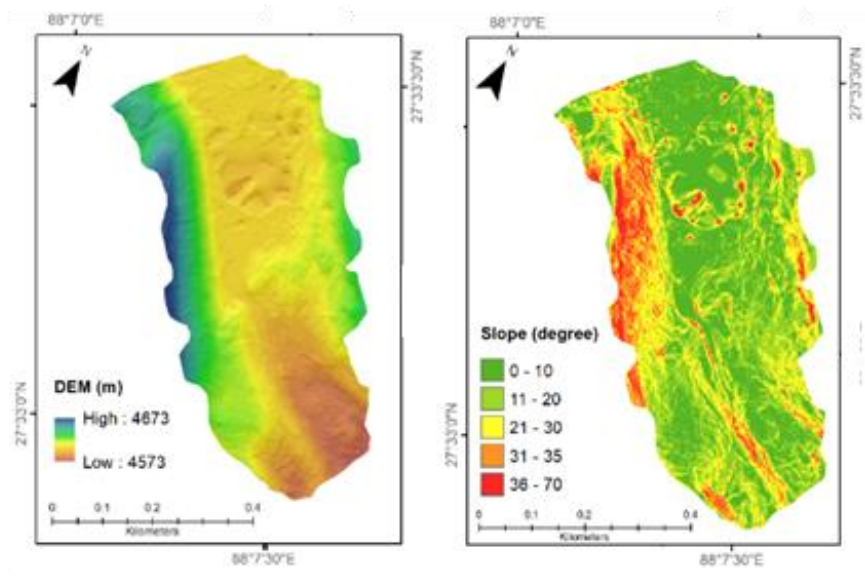

c) Hamtah
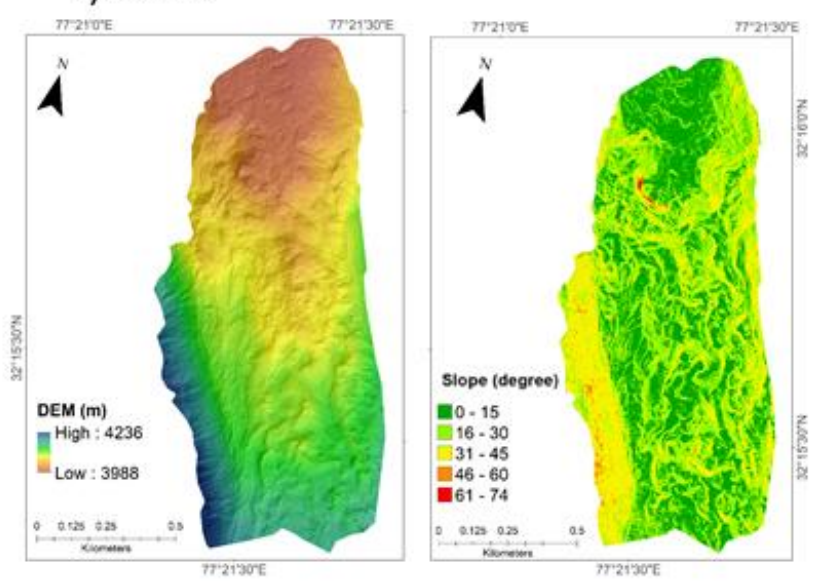

d) Panchinala-A

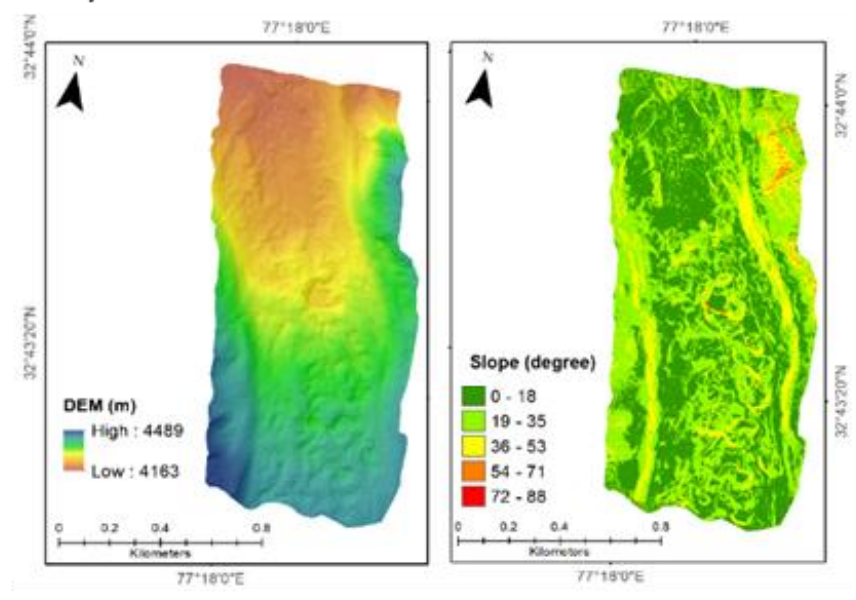

Figure 5: Surface DEM (left) and Slope (right) maps of the UAV surveyed sites of a) East Rathong (ER1) and b) East Rathong (ER2), c) Hamtah and d) Panchinala-A sites. The background of the DEMs contains their own hillshade maps.

\subsubsection{Glacier Surface Feature Maps}

Some prominent glacier surface features that are visible in UAV-derived ortho-mosaicked images are visually interpreted to generate glacier surface features maps for each surveyed glaciers.

East Rathong: Figure 6 shows the East Rathong glacier area (ER1) of UAV-derived orthomosaicked image. Here glacier ice is found to be exposed at the middle portion of the surveyed glacier area. Glacier landforms such as crevasse (Figure 6a) and ridges are observed along the slightly curved glacier trunk, where the glacier ice is exposed. Meltwater streams are found to be moving from higher elevations towards the lower elevations (Figure 6b). Supraglacial ponds/lakes partially surrounded by ice-cliffs are observed at the debris-area located lower 
elevations glacier surveyed area (Figures $6 c$ and $6 \mathrm{~d}$ ). Non-linear fractures were dominant on the exposed glacier ice and at some parts of debris-area at higher elevations (Figure 6e). These meltwater streams end up at glacier infills in between and continue flowing in the subsurface towards the glacier snout direction. The glacier ice is less exposed and mostly covered by supraglacial debris at lateral sides and bottom of the surveyed area. Most of the ice-cliffs are found to be covered by debris (Figure 6e). By visually identifying these features in the orthomosaicked images, glacier surface feature map is then generated (Figure 7).

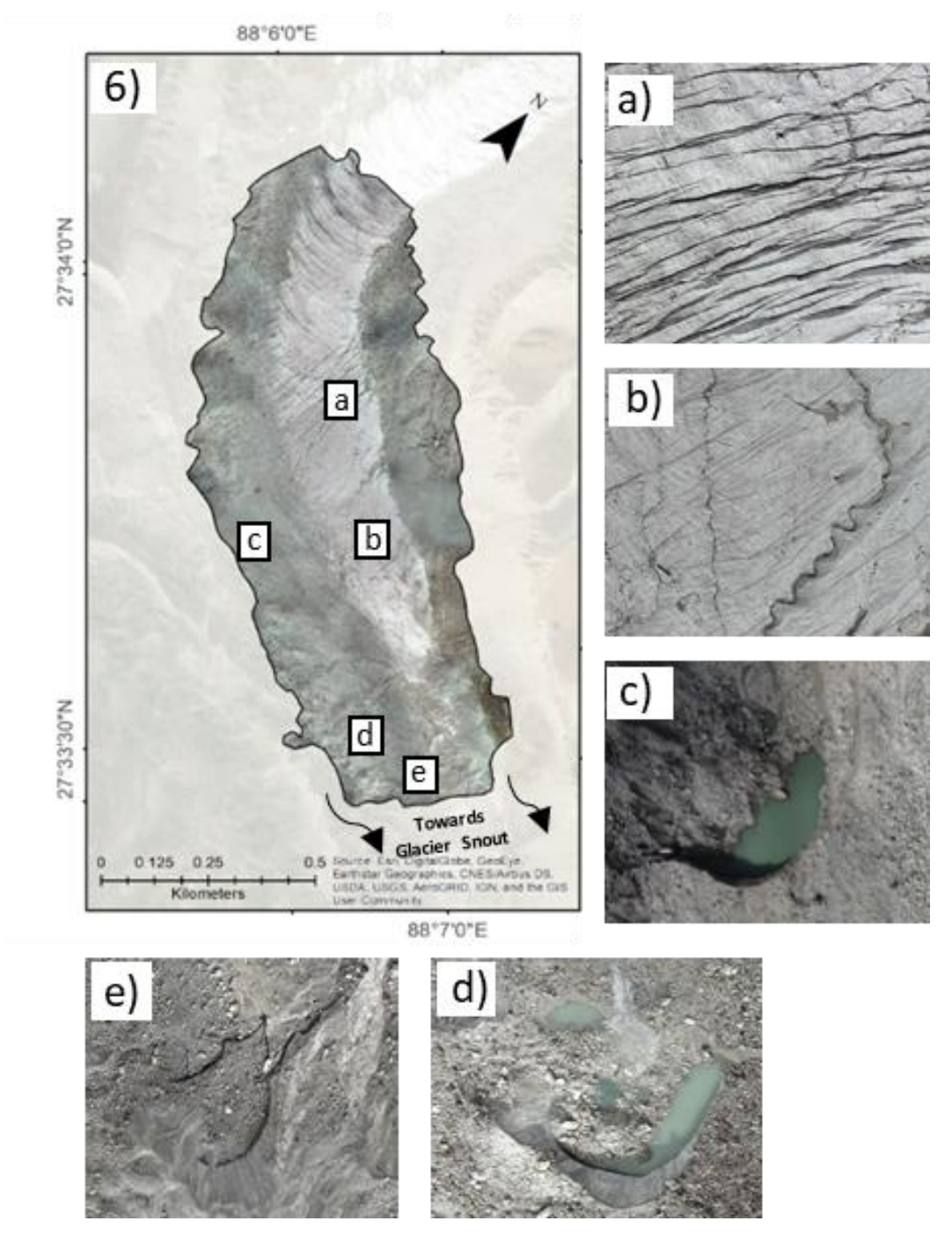

Figure 6: Map of ortho-mosaicked image (10 cm GSD) of East Rathong glacier site (ER1). The samples of identified glacier features from the ortho-mosaicked image show small portion of crevasses (a), visible meltwater streams and small fractures (b), supraglacial ponds/lakes surrounded by ice-cliffs $(\mathrm{c}, \mathrm{d})$ and supraglacial debris covering the glacier surface and ice-cliffs (e). Background image source: Esri, DigitalGlobe, GeoEye, i-cubed, USDA FSA, USGS, AEX, Getmapping, Aerogrid, IGN, IGP, swisstopo, and the GIS User Community 


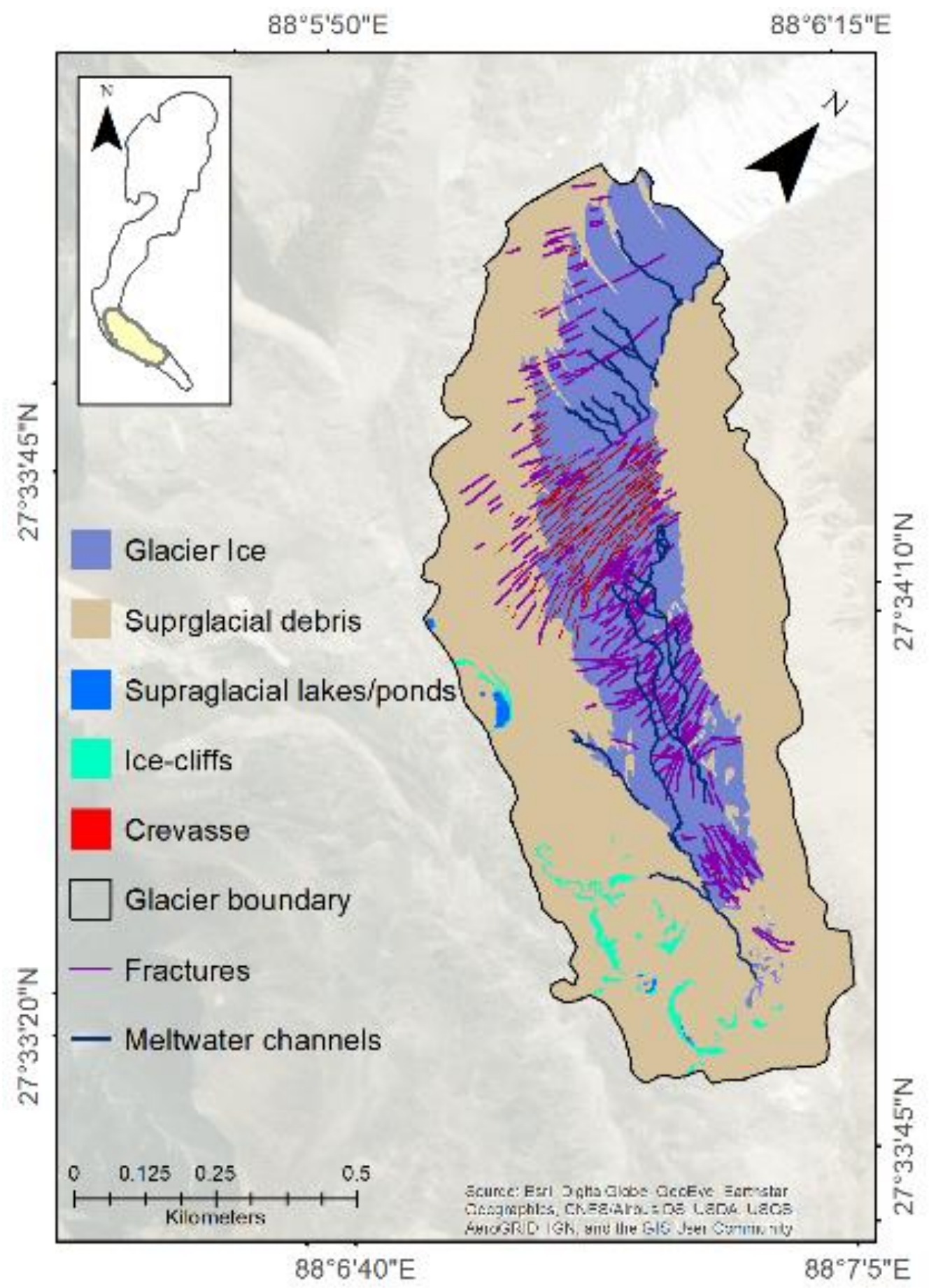

Figure 7: Glacier surface feature map generated from UAV-derived ortho-mosaicked images at East Rathong site (ER1). The inset map shows glacier boundary and glacier covered area by UAV (light yellow color). Background image source: Esri, DigitalGlobe, GeoEye, i-cubed, USDA FSA, USGS, AEX, Getmapping, Aerogrid, IGN, IGP, and the GIS User Community. 
Hamtah: Figure 8 shows the Hamtah glacier area of UAV-derived ortho-mosaicked image. Two glacier features such as supraglacial debris and ice-cliffs (Figures 8a-8d) are identified. The glacier surface is found to have more undulations due to heavy debris (Figure 8c). Figure $8 \mathrm{~b}$ shows the steep walls adjoining the lateral part of the glacier, where the rockfall event has occurred previously. Ice-cliffs are observed near the snout region and at the higher elevations of the surveyed glacier site (Figures $8 \mathrm{a}$ and $8 \mathrm{~d}$ ). No supraglacial ponds are found within the surveyed area which indicates that the velocity of the glacier may be active in these areas. By visually identifying these features in the ortho-mosaicked images, glacier surface feature map is then generated (Figure 9).

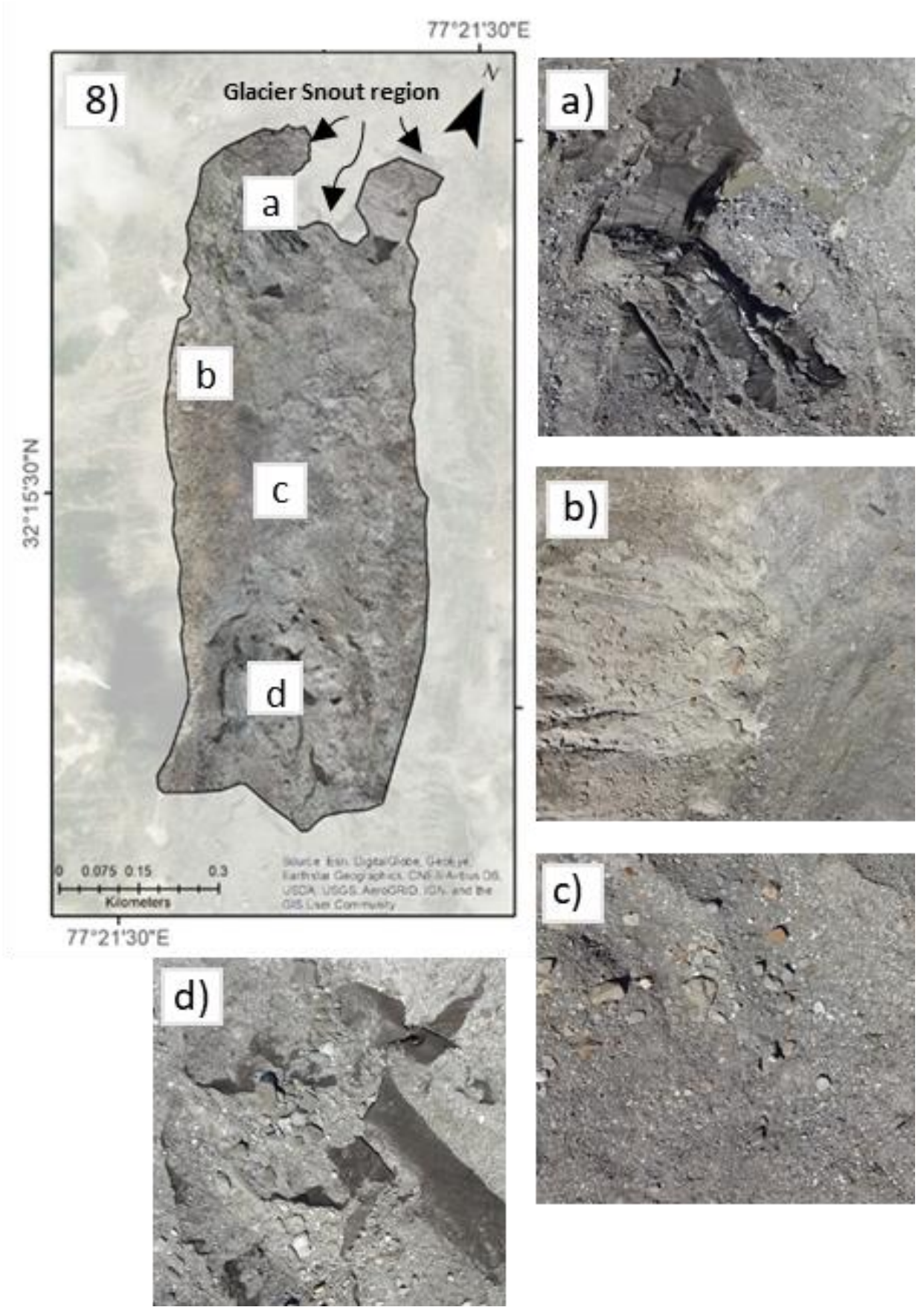


Figure 8: Map of ortho-mosaicked image $(10 \mathrm{~cm} \mathrm{GSD})$ of the Hamtah glacier site. The samples of identified glacier features from the ortho-mosaicked image shows ice-cliffs (a,d) and supraglacial debris at lateral side (b) and at middle portion (c) of the glacier area. Background image source: Esri, DigitalGlobe, GeoEye, i-cubed, USDA FSA, USGS, AEX, Getmapping, Aerogrid, IGN, IGP, and the GIS User Community.

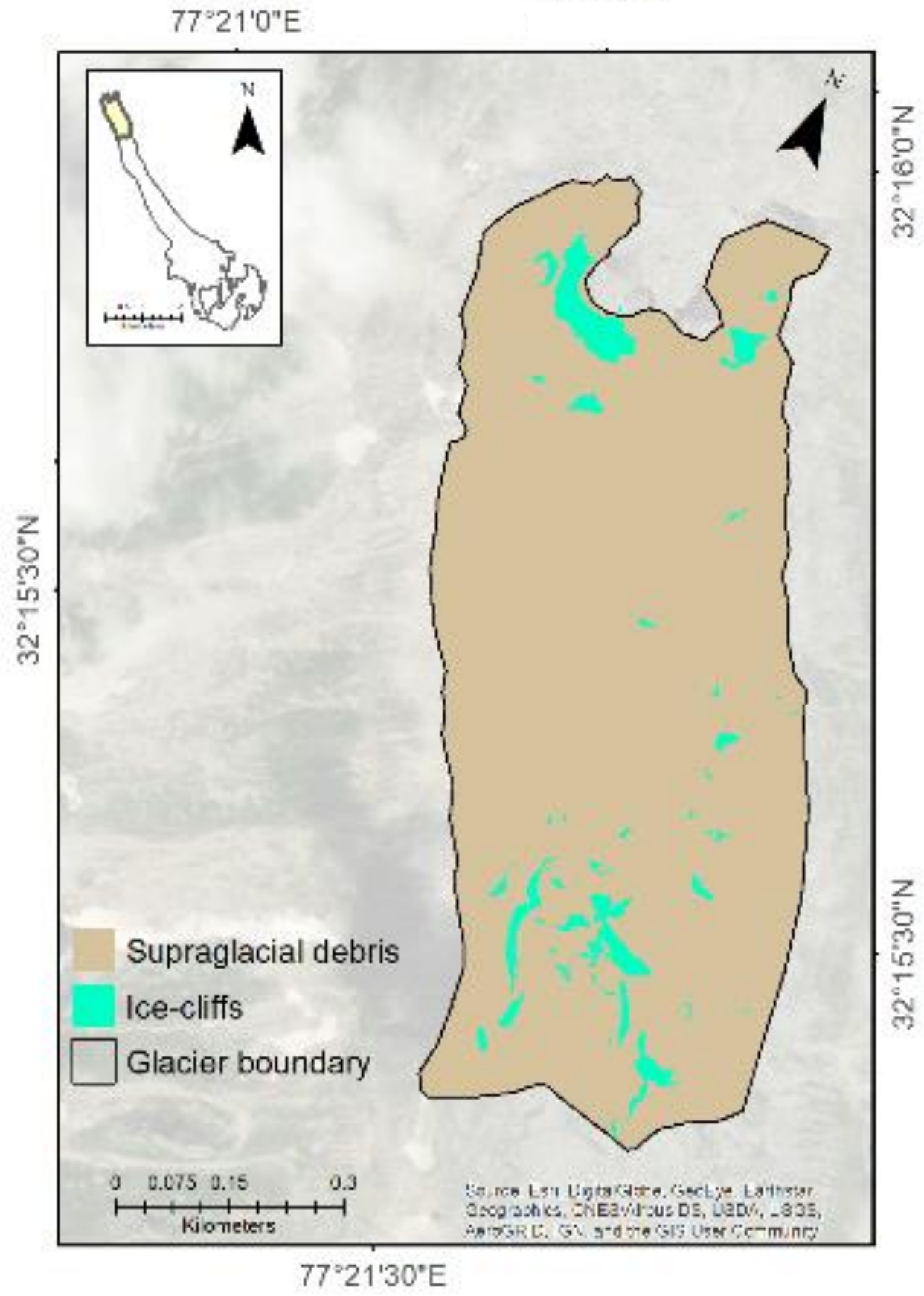

Figure 9: Glacier surface feature map generated from UAV-derived ortho-mosaicked images at Hamtah. The inset map shows glacier boundary and glacier covered area by UAV (light yellow color). Background image source: Esri, DigitalGlobe, GeoEye, i-cubed, USDA FSA, USGS, AEX, Getmapping, Aerogrid, IGN, IGP, and the GIS User Community. 
Panchinala-A: Figure 10 shows the Panchinala-A glacier area of UAV-derived orthomosaicked image. Glacier features like ice-cliffs (Figures 10a-10d), supraglacial lakes/ponds, snow-cover and supraglacial debris are identified. The supraglacial lakes/ponds partially covered by snow/ice are found to be surrounded by ice-cliffs (Figures 10b and 10c). The presence of supraglacial lakes/ponds within the surveyed area of the glacier surface shows that the glacier is stagnant or moving very slow. Supraglacial debris is covered by snow in most of the glacier surface. Compared to other surveyed glaciers, few numbers of supraglacial lakes/ponds are identified in UAV surveyed area of the Panchinala-A glacier. By visually identifying these features in the ortho-mosaicked images, glacier surface feature map is generated (Figure 11).
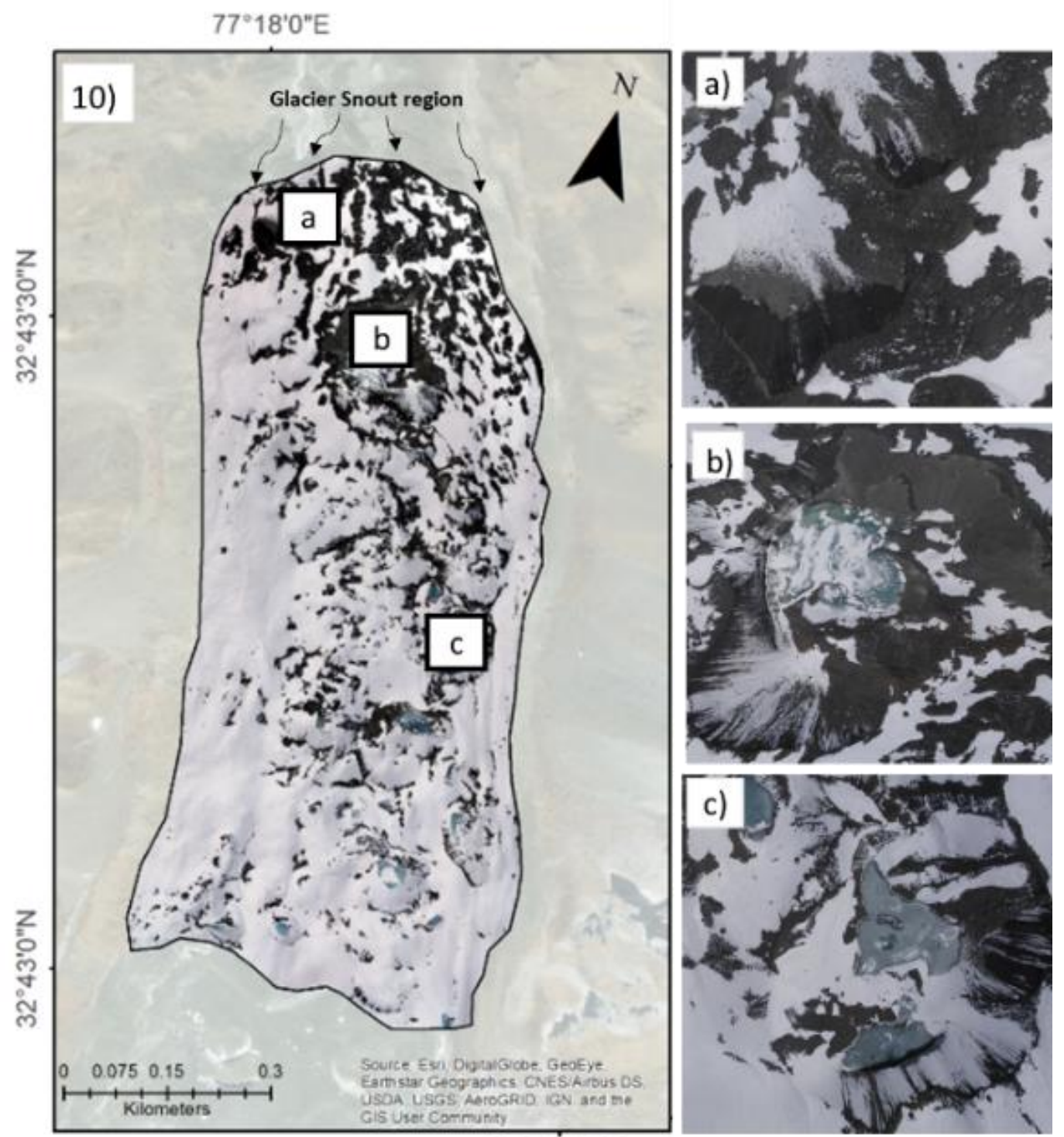

\section{$77^{\circ} 18^{\prime} 30^{\prime \prime} \mathrm{E}$}

Figure 10: Map of ortho-mosaicked image (10 cm GSD) of the Panchinala-A glacier site. The samples of identified glacier feature from the ortho-mosaicked image show ice-cliffs (a-c), supraglacial debris covered by snow (a) and surrounding supraglacial ponds/lakes (b and c). 
Background image source: Esri, DigitalGlobe, GeoEye, i-cubed, USDA FSA, USGS, AEX, Getmapping, Aerogrid, IGN, IGP, and the GIS User Community.

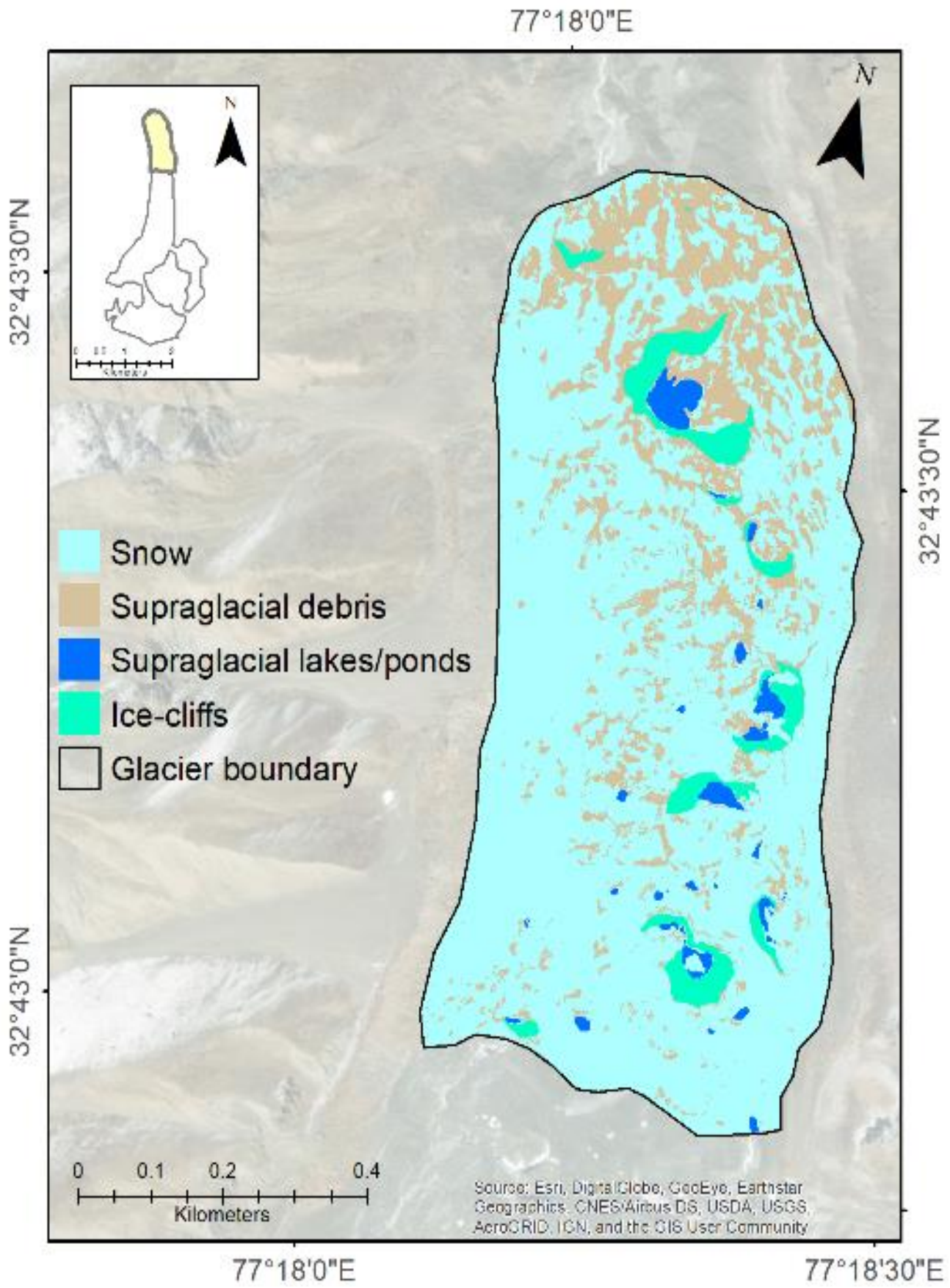

Figure 11: Glacier surface feature map generated from UAV-derived ortho-mosaicked images at Panchinala-A. The inset map shows glacier boundary and glacier covered area by UAV (light yellow color). Background image source: Esri, DigitalGlobe, GeoEye, i-cubed, USDA FSA, USGS, AEX, Getmapping, Aerogrid, IGN, IGP, and the GIS User Community. 


\section{Discussions}

\subsection{Challenges Faced during the UAV Data Acquisition}

The challenges experienced during UAV data acquisition over the three glacier sites are studied and reported here.

East Rathong: During the UAV survey, the UAV's GNSS module was able to receive fewer satellite signals (3-4 satellites) throughout the survey because of the obstructions from steep walls surrounding the glacier. Moreover, low air density made the UAV to land faster than the average speed. As a result, UAV landed 20-30m away from the assigned location, which caused damages like cracks on the central body and edges of fixed wings. In total, six GCPs were collected, but only one GCP was collected within the ER1, i.e. glacier region of the surveyed area. Remaining five GCPs were at the ER2 region where UAV trial survey was conducted on 2 October 2017 before flying the UAV on glacier surface. Due to the poor GNSS satellite signal availability, the vertical (horizontal) RMSE of DEM was observed to be $31.83 \mathrm{~m}(1.74 \mathrm{~m})$. However, after using GCPs at ER2, the vertical (horizontal) RMSE was reduced to $1.49 \mathrm{~m}$ (0.04 m).

Hamtah: Here the glacier's valley surrounded by steep walls are comparatively steeper than East Rathong glacier valley. Such terrain conditions restricted the UAV's GNSS module to receive fewer satellite signals (3-4 satellites) which were similar to that of UAV survey at East Rathong. UAV take-off location was chosen outside the glacier region, as there was no appropriate place found for UAV take-off and landing around the glacier terminus region. During the flight, the link between UAV and GCS was lost for about twenty to thirty seconds because of steep wall glacier valleys and hence, UAV's mission was called off. After several attempts, UAV took off again but still received only three to four GNSS satellites throughout the survey. Unexpectedly, the sudden change in weather followed by heavy snowfall in subsequent days led us to abort the planned missions. During the DGPS survey, 15 GCPs were collected (see Figure 4b), but only five GCPs were lying inside the UAV surveyed glacier site. Unlike natural targets used in the East Rathong glacier, here artificial targets (see Figure 4b) were used for collecting GCPs. The steep-walled glacier valleys obstructed the UAV survey and led to cover a smaller surface area and also affected the accuracy of the UAV data products see Table 4. 
Panchinala-A: Here the glacier valley's terrain topographic condition is better than East Rathong and Hamtah glaciers. Therefore, UAV's GNSS module was able to acquire 9-12 satellite signals. The remaining snow-free area was covered by debris and boulders. Considering the safety of the UAV, snow covered location was chosen for landing. However, the ground sensor module of UAV identified snow as an obstruction and took additional time to hover around and then finally landed on the heavy debris surface away from the fixed location. As a result, UAV faced major damages (i.e. servo connection mechanism which connects aileron of wings with the central body of UAV). Therefore, to avoid such damages it is recommended to turn-off the UAV's ground sensor at the time of landing.

Based on these observations at three glacier sites, it can be said that the challenges faced during UAV data acquisition on glacier sites vary due to i) nature of terrain and ii) choice of UAV take-off/landing locations. Therefore, the study strongly suggests to select favourable take-off and landing locations while conducting fixed-wing UAV surveys on high mountain glaciers. Table 7 summarizes the challenges faced by fixed-wing UAV (eBee plus) during their data acquisition on three study glacier sites.

Table 7: Summary of the problems faced by fixed-wing UAV (eBee plus) during data acquisition on three study glacier sites, their causes and implications.

\begin{tabular}{|l|l|l|l|}
\hline \multicolumn{1}{|c|}{ Glaciers } & \multicolumn{1}{|c|}{ Problems faced } & \multicolumn{1}{c|}{ Causes } & \multicolumn{1}{c|}{ Implications } \\
\hline $\begin{array}{l}\text { East Rathong } \\
\text { ER1 and } \\
\text { ER2 sites })\end{array}$ & $\begin{array}{l}\text { Low GNSS signal } \\
\text { reception } \\
\text { (3-4 GNSS station } \\
\text { signals). }\end{array}$ & $\begin{array}{l}\text { Steep valleys at } \\
\text { lateral sides of the } \\
\text { glacier }\end{array}$ & $\begin{array}{l}\text { Low DEM accuracy (without } \\
\text { GCP targets); } \\
\text { UAV landed 20-30m away from } \\
\text { the target location; minor } \\
\text { damages on UAV }\end{array}$ \\
\hline Hamtah & $\begin{array}{l}\text { Low GNSS signal } \\
\text { reception } \\
\text { (3-4 GNSS station } \\
\text { signals); } \\
\text { UAV-Ground station link } \\
\text { off ( 30 seconds). }\end{array}$ & $\begin{array}{l}\text { Steep valleys at } \\
\text { lateral sides of the } \\
\text { glacier. }\end{array}$ & $\begin{array}{l}\text { Low DEM accuracy (without } \\
\text { GCP targets); } \\
\text { UAV landed 40-50m away from } \\
\text { the target location }\end{array}$ \\
\hline Panchinala-A A & $\begin{array}{l}\text { UAV crash landed on } \\
\text { boulders rather than } \\
\text { landing at assigned } \\
\text { location on snow covered } \\
\text { area. }\end{array}$ & $\begin{array}{l}\text { Snow cover (at } \\
\text { landing location) } \\
\text { was identified as } \\
\text { obstruction by } \\
\text { UAV's ground } \\
\text { sensor. }\end{array}$ & $\begin{array}{l}\text { Delayed UAV landing and major } \\
\text { damages to servo connection } \\
\text { mechanism (connects aileron } \\
\text { with the central body of UAV). }\end{array}$ \\
\hline
\end{tabular}




\subsection{Recommended UAV Take-off/Landing Locations}

From the experiences gained during the UAV surveys at the three glacier sites, the study realises the importance of the site selection for UAV take-off and landing. When such sites are located, during fixed-wing UAV surveys (standalone GNSS mode) one can expect good satellite signal reception and avoid damages of the UAV hardware parts. In general, the UAV manufacturer (Sensefly, Original Equipment Manufacturer of eBee plus) recommends to perform take-off and landing the UAVs on a flat surface/mildly sloped terrains with $30 \mathrm{~m}$ offset around take-off/landing location and keep the ground sensor off (if present) to avoid damages. However, based on the knowledge gained from the challenges faced during the UAV surveys at three different glacier sites, it is suggested to choose relatively flatter surface preferably surface slope below six degrees. Similarly, instead of $30 \mathrm{~m}$ at least $50 \mathrm{~m}$ offset should be maintained around the identified UAV take-off/landing location to ensure minimum damages to UAV.

At the same time, it is observed that a single flight above 4000 m.a.s.l. may take $\sim 20-40$ minutes to cover $1.00-1.50 \mathrm{~km}^{2}$ area with an average flying altitude $\sim 175 \mathrm{~m}$ above the ground level (provided clear sky conditions, wind speed between $2 \mathrm{~ms}^{-1}$ and $10 \mathrm{~ms}^{-1}$, good GNSS satellite signal strength with low Dilution of Precision (DOP)). Accordingly, the study assumes that in glaciers located at such high altitudes having low temperatures, thin air density and relatively high wind speeds, $5-8 \mathrm{~km}^{2}$ of glacier area can be covered using fixed-wing UAVs (such as eBee series) in a single day during ablation season.

Based on these observations, the study has identified three potential sites favourable for UAV take-off and landing on Himalayan valley-type glaciers.

Top of the Glacier Valley: In valley glaciers, the study recommends to conduct the UAV survey from the valley top adjacent to the glacier rather than the glacier surface region. Surveying from the glacier surface, UAV may use around $15 \%-30 \%$ of the battery power only to reach the desired altitude and landing after the end of the survey. When the UAV survey is conducted from the flatter/low relief regions (if available) of the valley top adjacent to the glacier, battery power used by the UAV and its flight time to reach the maximum altitude and landing can be significantly reduced. As a result, more time can be allocated to cover additional glacier area with the same flight conditions. Moreover, UAVs tend to have better visibility of the glacier, and it can acquire good satellite coverage with low DOP. In such cases, one can 
reduce the number of flight attempts and minimise the risk of damages. However, to identify such locations, the guidance of field experts is essential.

Near the Equilibrium Line Altitude (ELA): When no such locations as recommended above are identified on the valley top adjacent to the glacier, the area near the ELA region in the glacier should be considered. Usually, the ELA region in Himalayan glaciers has wide crosssections and exposed with hard ice without any debris cover. Hence, the landing of a UAV (fixed wing) on hard ice would have minimum impact on UAV than the debris area. Moreover, the chances for maximum GNSS satellite signal receptions and the probability of covering a larger area are also better, i.e. UAV flights can cover both the accumulation and ablation regions from the same take-off and landing location.

Near the Terminus and Ablation Region: When the above two regions are not possible to occupy, then adjacent regions of ablation zones, glacier terminus, and nearby downstream areas should be considered. Generally, the terminus of the valley glaciers has narrow cross-sectional width and more terrain undulations than the ELA regions, which limits the coverage area of UAV survey to the ablation region and has lesser probability of covering an entire glacier in a single flight if the glacier is $>1 \mathrm{~km}^{2}$. However, fixed-wing UAVs will be able to cover an entire glacier in a single flight under ideal flying conditions, if the glacier's, i) area less than $1 \mathrm{~km}^{2}$, ii) elevation range is within $1 \mathrm{~km}$ and iii) terrain has low relief valley similar to Panchinala-A glacier.

By following the above recommendations on mountain glaciers, it is expected that an UAV can cover a large area with less number of flights, minimise UAV's physical damages during landing, acquire good GNSS satellite signals and also possible to derive accurate orthomosaicked images and DEMs.

\section{Summary and Conclusions}

This article reports the authors experiences obtained from UAV surveys conducted using fixedwing off-the-shelf UAV (eBee plus) on the glaciers located in Western and Eastern Indian Himalayas. Automated UAV surveys were able to cover the rugged and harsh terrains of the ablation zone across East Rathong glacier (October 2017), Hamtah glacier (September 2018) and Panchinala-A glacier (June 2019). To the best of our knowledge, this is the first study 
which addresses few challenges in UAV surveys in High Mountain Asia and specifically in Indian Himalayan Region.

From the UAV collected photos, ultra-high spatial resolution (0.1m GSD) DEMs and orthomosaicked images were generated by Pix4D professional photogrammetry software. UAVderived DEM was able to achieve vertical (horizontal) accuracy of $0.45 \mathrm{~m}$ and $0.21 \mathrm{~m}(0.15 \mathrm{~m}$ and $0.1 \mathrm{~m}$ ) with 3 and 6 GCPs for an area of $0.75 \mathrm{~km}^{2}$ and $1.38 \mathrm{~km}^{2}$. The study assessed the accuracy of UAV-derived DEMs with and without GCPs. Results point out that UAV-derived DEMs without GCPs are highly prone to errors at sites where steep-walled valleys exists like in East Rathong and Hamtah. At the same time, the DEMs are less prone to errors in low relief valley terrains such as in Panchinala-A site. These observations show that GCPs are essential to achieve decimetre level accuracy at complex terrain conditions. The study also demonstrated the utility of ortho-mosaicked images by identifying the glacier features and complex landforms like supraglacial debris, ice-cliffs, fractures, meltwater channels, crevasses and supraglacial lakes/ponds for generating glacier surface feature maps.

From the UAV surveying experiences on three glacier sites, the study showcases that choosing appropriate locations for UAV take-off and landing is one of the crucial aspects for a successful UAV survey. Furthermore, the study recommends strategies for choosing appropriate takeoff/landing locations for UAVs, especially for fixed-wing UAVs. By following these recommendations, one can optimise the flight endurance, i.e. good GNSS satellite signal availability, minimise number of flights and increase coverage area on high mountain glaciers. The knowledge developed from this study can be valuable information to the glaciologists and hydrologists, who are interested in using UAVs for mapping and monitoring of glaciers in the Himalayan region and possibly beyond. However, the major limitation of the fixed-wing UAV is its inability to take-off or land vertically. Care should be taken to avoid take-off and landing fixed-wing UAVs on the glacier surface where steep slopes and heavy debris exists. 


\section{Author Contributions:}

R.R and P.J.N designed the experiments. R.R, P.J.N and A.D contributed to field data collection. R.R and P.J.N, processed the data, analysed the results and wrote the manuscript with the contributions from A.D and A.K.

\section{Funding:}

This study was funded by Ministry of Human Resource Development (MHRD) and Ministry of Earth Sciences (MOES), Government of India for the project titled "RISK ASSESSMENT OF MORAINE DAMMED GLACIER LAKES DUE TO CLIMATE CHANGE" (Project Number: 4096) under the scheme called IMPacting Research INnovation and Technology (IMPRINT) scheme.

\section{Acknowledgement:}

The authors acknowledge Sakura Geoinformation Software Research Pvt. Ltd. Chennai and their team for providing UAV related training and their support during field investigations. The authors thank Dr Ankur Pandit, Dr Prateek Gantayat, Mr Abhijit Chhatry, Ms Sangita Singh, Mr Vivek Sharma, Ms Smarika Kulshrestha and Ms Anisha Narendran from HydroRemote Sensing Applications (H-RSA) Group, Department of Civil Engineering, Indian Institute of Technology Bombay for being part of the field investigations. The author would like to thank all the porters individually from Red Panda and Travel Himalayas for assisting us throughout the fieldwork and a special thanks to Adhikari Ji for guiding us to reach the glacier sites and his invaluable help during field measurements at Panchinala-A glacier.

\section{Conflicts of Interest}

The authors declare no conflict of interest. The funders had no role in the design of the study; in the collection, analyses, or interpretation of data; in the writing of the manuscript, or in the decision to publish the results. 


\section{References:}

1. Maurer, J.M.; Schaefer, J.M.; Rupper, S.; Corley, A. Acceleration of ice loss across the Himalayas over the past 40 years. Sci. $A d v$. 2019, 5(6), p.eaav7266. DOI: 10.1126/sciadv.aav7266.

2. Strozzi, T.; Kääb, A.; Frauenfelder, R. Detecting and quantifying mountain permafrost creep from in situ inventory, space-borne radar interferometry and airborne digital photogrammetry. Int. J. Remote Sens. 2004, 25(15), 2919-2931; DOI: $10.1080 / 0143116042000192330$.

3. Haeberli, W.; Hoelzle, M.; Paul, F.; Zemp, M. Integrated monitoring of mountain glaciers as key indicators of global climate change: The European Alps. Ann. Glaciol. 2007, 46, 150-160; DOI:10.3189/172756407782871512.

4. Vincent, C.; Ramanathan, A.; Wagnon, P.; Dobhal, D.P.; Linda, A.; Berthier, E.; Sharma, P.; Arnaud, Y.; Azam, M.F.; Jose, P.G.; Gardelle, J. Mass gain of glaciers in Lahaul and Spiti region (North India) during the nineties revealed by in-situ and satellite geodetic measurements. Cryosphere. 2012, 6(5), 3733-3755; DOI: 10.5194/tcd-6-3733-2012.

5. Wang, P.; Li, Z.; Jin, S.; Zhou, P.; Yao, H.; Wang, W. Ice thickness, volume and subglacial topography of Urumqi Glacier No. 1, Tianshan mountains, central Asia, by ground penetrating radar survey. J Earth Syst Sci. 2014, 123(3), 581-591; DOI:10.1007/s12040014-0421-4.

6. Bhardwaj, A.; Joshi, P.K.; Sam, L.; Snehmani. Remote sensing of alpine glaciers in visible and infrared wavelengths: a survey of advances and prospects. Geocarto Int. 2015, 31(5), 557-574; DOI:10.1080/10106049.2015.1059903.

7. Yordanov, V.; Fugazza, D.; Azzoni, R.S.; Cernuschi, M.; Scaioni, M.; Diolaiuti, G.A. Monitoring alpine glaciers from close-range to satellite sensors. ISPRS J Photogramm Remote Sens. 2019, 1803-1810; DOI:10.5194/isprs-archives-xlii-2-w13-1803-2019

8. Zemp, M.; Nussbaumer, S. U.; GärtnerRoer, I.; Huber, J.; Machguth, H.; Paul, F.; Hoelzle, M. (eds.), ICSU(WDS)/IUGG(IACS)/UNEP/UNESCO/WMO, World Glacier Monitoring 
Service, Zurich, Switzerland. WGMS. Global Glacier Change Bulletin No. 2 (20142015). 2017, 244; publication based on database version DOI: 10.5904/wgms-fog-201710.

9. Bajracharya, S.R.; Maharjan, S.B.; Shrestha, F. Understanding dynamics of Himalayan glaciers: scope and challenges of remote sensing. The International Archives of Photogrammetry, Remote Sensing and Spatial Information Sciences. 2014, 40(8), 1283; DOI:10.5194/isprsarchives-xl-8-1283-2014.

10. Pajares, G. Overview and current status of remote sensing applications based on unmanned aerial vehicles (UAVs). Photogramm Eng Remote Sensing. 2015, 81(4), 281-330; DOI:10.14358/pers.81.4.281.

11. Yao, H.; Qin, R.; Chen, X. Unmanned aerial vehicle for remote sensing applications-A review. Remote Sens. 2019, 11(12), 1443; DOI:10.3390/rs11121443.

12. Bhardwaj, A.; Sam, L.; Martín-Torres, F.J.; Kumar, R. UAVs as remote sensing platform in glaciology: Present applications and future prospects. Remote Sens. Environ. 2016, 175, 96-204; DOI: 10.1016/j.rse.2015.12.029.

13. Buri, P.; Miles, E.S.; Steiner, J.F.; Immerzeel, W.W.; Wagnon, P.; Pellicciotti, F. A physically based 3-D model of ice cliff evolution over debris-covered glaciers. J. Geophys. Res. Earth Surf. 2016, 121(12), 2471-2493; DOI:10.1002/2016jf004039.

14. Kraaijenbrink, P.D.A.; Shea, J.M.; Pellicciotti, F.; De Jong, S.M.; Immerzeel, W.W. Object-based analysis of unmanned aerial vehicle imagery to map and characterise surface features on a debris-covered glacier. Remote Sens. Environ. 2016, 186, 581-595; DOI: 10.1016/j.rse.2016.09.013.

15. Wigmore, O.; Mark, B.G. Monitoring tropical debris-covered glacier dynamics from highresolution unmanned aerial vehicle photogrammetry, Cordillera Blanca, Peru. Cryosphere. 2017, 11, 2463; DOI: 10.5194/tc-11-2463-2017. 
16. Bodin, X.; Thibert, E.; Sanchez, O.; Rabatel, A.; Jaillet, S. Multi-Annual Kinematics of an Active Rock Glacier Quantified from Very High-Resolution DEMs: An Application-Case in the French Alps. Remote Sens. 2018, 10(4), 547; DOI: 10.3390/rs10040547.

17. Fugazza, D.; Scaioni, M.; Corti, M.; D’Agata, C.; Azzoni, R.S.; Cernuschi, M.; Smiraglia, C.; Diolaiuti, G.A. Combination of UAV and Terrestrial Photogrammetry to Assess Rapid Glacier Evolution and Map Glacier Hazards. Nat Hazard Earth Sys. 2018, 18, 1055-1071; DOI: 10.5194/nhess-18-1055-2018.

18. Kaufmann, V.; Seier, G.; Sulzer, W.; Wecht, M.; Liu, Q.; Lauk, G.; Maurer, M. Rock Glacier Monitoring Using Aerial Photographs: Conventional vs. UAV-based Mapping-A Comparative Study. International Archives of the Photogrammetry, Remote Sensing and Spatial Information Sciences. 2018, 239-246; DOI: 10.5194/isprs-archives-xlii-1-2392018.

19. Mark, B.G.; French, A.; Baraer, M.; Carey, M.; Bury, J.; Young, K.R.; Polk, M.H.; Wigmore, O.; Lagos, P.; Crumley, R.; McKenzie, J.M. Glacier Loss and Hydro-Social Risks in the Peruvian Andes. Global and Planetary Change. 2017, 159, 61-76; DOI: 10.1016/j.gloplacha.2017.10.003.

20. Vivero, S.; Lambiel, C. Monitoring the crisis of a rock glacier with repeated UAV surveys. Geographica Helvetica. 2019, 74(1), 59-69; DOI: 10.5194/gh-74-59-2019.

21. Immerzeel, W.W.; Kraaijenbrink, P.D.A.; Shea, J.M.; Shrestha, A.B.; Pellicciotti, F.; Bierkens, M.F.P.; De Jong, S.M. High-resolution monitoring of Himalayan glacier dynamics using unmanned aerial vehicles. Remote Sens. Environ. 2014, 150, 93-103; DOI: 10.1016/j.rse.2014.04.025.

22. Vincent, C., Wagnon, P., Shea, J., Immerzeel, W., Kraaijenbrink, P., Shrestha, D., Soruco, A., Arnaud, Y., Brun, F., Berthier, E. Sherpa, S. Reduced melt on debris-covered glaciers: investigations from Changri Nup Glacier, Nepal. Cryosphere. 2016, 10, 1845-1858; DOI: 10.5194/tc-10-1845-2016.

23. Kraaijenbrink, P.; Meijer, S.W.; Shea, J.M.; Pellicciotti, F.; De Jong, S.M.; Immerzeel, W.W. Seasonal Surface Velocities of a Himalayan Glacier Derived by Automated 
Correlation of Unmanned Aerial Vehicle Imagery. Ann. Glaciol. 2016, 57(71), 103-113. DOI: $10.3189 / 2016 \operatorname{aog} 71 \mathrm{a} 072$.

24. Kraaijenbrink, P.D.; Shea, J.M.; Litt, M.; Steiner, J.F.; Treichler, D.; Koch, I.; Immerzeel, W.W. Mapping Surface Temperatures on a Debris-Covered Glacier with an Unmanned Aerial Vehicle. Front. Earth Sci. 2018, 6, 64; DOI:10.3389/feart.2018.00064.

25. Brun, F.; Wagnon, P.; Berthier, E.; Shea, J. M.; Immerzeel, W. W.; Kraaijenbrink, P. D. A.; Vincent, C.; Reverchon, C.; Shrestha, D.; Arnaud, Y. Ice Cliff Contribution to the Tongue-Wide Ablation of Changri Nup Glacier, Nepal, Central Himalaya. Cryosphere. 2018, 12, 3439-3457; DOI: 10.5194/tc-12-3439-2018.

26. Watson, C.S.; Kargel, J.S.; Shugar, D.H.; Haritashya, U.K.; Schiassi, E.; Furfaro, R. Mass loss from calving in Himalayan proglacial lakes. Front. Earth Sci. 2020, 7; DOI: 10.3389/feart.2019.00342.

27. Groos, A.R.; Bertschinger, T.J.; Kummer, C.M.; Erlwein, S.; Munz, L.; Philipp, A. The potential of low-cost UAVs and open-source photogrammetry software for high-resolution monitoring of Alpine glaciers: a case study from the Kanderfirn (Swiss Alps). Geosci. J. 2019, 9(8), 356; DOI:10.3390/geosciences9080356.

28. Ryan, J.C.; Hubbard, A.L.; Box, J.E.; Todd, J.; Christoffersen, P.; Carr, J.R.; Holt, T.O.; Snooke, N.A. UAV photogrammetry and structure from motion to assess calving dynamics at Store Glacier, a large outlet draining the Greenland ice sheet. Cryosphere. 2015, 9, 111; DOI: 10.5194/tc-9-1-2015.

29. Jouvet, G.; van Dongen, E.; Lüthi, M.P.; Vieli, A. In-situ measurements of the ice flow motion at Eqip Sermia glacier using a remotely controlled UAV. Geoscientific Instrumentation Methods and Data Systems. 2019, 9(1), 1-15; DOI: 10.5194/gi-9-1-2020.

30. Fugazza, D.; Senese, A.; Azzoni, R.S.; Smiraglia, C.; Cernuschi, M.; Severi, D.; Diolaiuti, G. High-Resolution Mapping of Glacier Surface Features. The UAV Survey of the Forni Glacier (Stelvio National Park, Italy). Geogr. Fis. Dinam. Quat. 2015, 28, 25-33; DOI: 10.4461/GFDQ.2015.38.03 
31. Rossini, M.; Di Mauro, B.; Garzonio, R.; Baccolo, G.; Cavallini, G.; Mattavelli, M.; De Amicis, M.; Colombo, R. Rapid Melting Dynamics of an Alpine Glacier with Repeated UAV Photogrammetry. Geomorphology. 2018, 304, 159-172; DOI: 10.1016/j.geomorph.2017.12.039.

32. Gindraux, S., Boesch, R. and Farinotti, D., 2017. Accuracy assessment of digital surface models from unmanned aerial vehicles' imagery on glaciers. Remote Sens. 2017, 9(2), 186; DOI:10.3390/rs9020186.

33. Jouvet, G.; van Dongen, E.; Lüthi, M.; Vieli, A. In Situ Measurements of the Ice Flow Motion at Eqip Sermia Glacier Using a Remotely Controlled Unmanned Aerial Vehicle (UAV). Geoscientific Instrumentation, Methods and Data Systems. 2019, 9(1),1-15; DOI:10.5194/gi-9-1-2020.

34. Chudley, T.R.; Christoffersen, P.; Doyle, S.H.; Abellan, A.; Snooke, N., 2019. Highaccuracy UAV photogrammetry of ice sheet dynamics with no ground control. Cryosphere. 2019,13, 955-968; DOI: 10.5194/tc-13-955-2019.

35. Racoviteanu, A.; Arnaud, Y.; Williams, M.W.; Manley, W.F. Spatial patterns in glacier characteristics and area changes from 1962 to 2006 in the Kanchenjunga-Sikkim area, eastern Himalaya. Cryosphere. 2014. 8(4), 3949-3998; DOI:10.5194/tcd-8-3949-2014.

36. Department of Science \& Technology and Climate change, Government of Sikkim, R\&D activities on Climate Change. Available online: http://dstsikkim.gov.in/R\&D\%20activities\%20.html (accessed on 21 June 2020)

37. Azam, M.F., Wagnon, P., Berthier, E., Vincent, C., Fujita, K. and Kargel, J.S., 2018. Review of the Status and Mass Changes of Himalayan-Karakoram Glaciers. J. Glaciol. 2018, 64(243), 61-74; DOI: 10.1017/jog.2017.86.

38. Monitoring Snow and Glaciers of Himalayan Region, Space Applications Centre (SAC), ISRO, Ahmedabad, India. SAC. 2016, 245; ISBN: 978 - 93 - 82760 - $24-5$. 
39. Ewertowski, M.; Tomczyk, A.; Evans, D.; Roberts, D.; Ewertowski, W. Operational framework for rapid, very-high resolution mapping of glacial geomorphology using lowcost unmanned aerial vehicles and structure-from-motion approach. Remote Sens. 2019, 11(1), 65; DOI: 10.3390/rs11010065. 